\title{
In vitro and in vivo antioxidant potential of milks, yoghurts, fermented milks and cheeses: a narrative review of evidence
}

\author{
Anthony Fardet* and Edmond Rock \\ INRA, JRU 1019, UNH, CRNH Auvergne, F-63000 Clermont-Ferrand \& Clermont Université, Université d'Auvergne, Unité de \\ Nutrition Humaine, BP 10448, F-63000 Clermont-Ferrand, France
}

\section{Abstract}

The antioxidant potential (AP) is an important nutritional property of foods, as increased oxidative stress is involved in most diet-related chronic diseases. In dairy products, the protein fraction contains antioxidant activity, especially casein. Other antioxidants include: antioxidant enzymes; lactoferrin; conjugated linoleic acid; coenzyme $\mathrm{Q}_{10}$; vitamins $\mathrm{C}, \mathrm{E}, \mathrm{A}$ and $\mathrm{D}_{3}$; equol; uric acid; carotenoids; and mineral activators of antioxidant enzymes. The AP of dairy products has been extensively studied in vitro, with few studies in animals and human subjects. Available in vivo studies greatly differ in their design and objectives. Overall, on a $100 \mathrm{~g}$ fresh weight-basis, AP of dairy products is close to that of grain-based foods and vegetable or fruit juices. Among dairy products, cheeses present the highest AP due to their higher protein content. AP of milk increases during digestion by up to 2.5 times because of released antioxidant peptides. AP of casein is linked to specific amino acids, whereas $\beta$-lactoglobulin thiol groups play a major role in the AP of whey. Thermal treatments such as ultra-high temperature processing have no clear effect on the AP of milk. Raw fat-rich milks have higher AP than less fat-rich milk, because of lipophilic antioxidants. Probiotic yoghurts and fermented milks have higher AP than conventional yoghurt and milk because proteolysis by probiotics releases antioxidant peptides. Among the probiotics, Lactobacillus casei/acidophilus leads to the highest AP. The data are insufficient for cheese, but fermentation-based changes appear to make a positive impact on AP. In conclusion, AP might participate in the reported dairy product-protective effects against some chronic diseases.

\section{Key words: Dairy products: Antioxidant potential: In vitro antioxidant activity: In vivo antioxidant activity: Processing}

\section{Introduction}

The antioxidant activity of foods is important for both their shelf life and protection from oxidative damage in the human body. Increased oxidative stress is involved in the onset of most age/ diet-related chronic diseases ${ }^{(1,2)}$. Therefore, antioxidant activity has been considered an essential nutritional property ${ }^{(3)}$. Its expression within the human body depends on the structure of the food matrix and density of food antioxidants, which both depend on the processing conditions, ultimately having an impact on the antioxidant bioavailability. Many in vitro assays have been proposed to estimate the antioxidant capacity of food. However, each method is based on different oxidoreduction reactions, yielding heterogeneous antioxidant potentials, as observed with the method used for milk ${ }^{(4)}$.

Overall, the antioxidant potential has been more widely studied in plant-based foods than in animal-based foods ${ }^{(5,6)}$. Probably the main reason for this is the lower average antioxidant potential of animal-based foods as compared with plant-based foods, i.e. on average 64 -fold less ${ }^{(6)}$. Thus, although being an important part of various diets worldwide, the antioxidant potential of dairy products has rarely been systematically measured $^{(6,7)}$. The most comprehensive study is that by Carlsen et $a l .{ }^{(6)}$ who measured antioxidant potential of eighty-six dairy products among more than 3100 foods, beverages, spices, herbs and supplements used worldwide. In addition, in epidemiological studies, the antioxidant potential of dairy products has not been investigated as the primary explanation for some of their protective effects, for example, against weight gain, type 2 diabetes, some CVD and some cancers ${ }^{(8)}$.

Dairy products contain antioxidant compounds in varying proportions depending on the matrix type (i.e. milks, yoghurts, fermented milks and cheeses) and processing (i.e. mechanical, thermal and fermentative). These compounds include both lipophilic and hydrophilic antioxidants: proteins (especially casein), peptides, antioxidant enzymes (i.e. superoxide dismutase (SOD), catalase and glutathione peroxidase), conjugated linoleic acid (CLA), coenzyme $\mathrm{Q}_{10}$, lactoferrin, vitamins $\left(\mathrm{C}, \mathrm{E}, \mathrm{A}\right.$ and $\left.\mathrm{D}_{3}\right)$, carotenoids, some minerals and some trace elements $^{(7,9)}$ (Fig. 1). According to Grażyna et al. ${ }^{(7)}$, the antioxidants in milk act in synergy by forming an antioxidant network, imparting high antioxidant potential to milk and effectively protecting milk fat against oxidation. In addition, although this is not a direct focus of the present review, the

Abbreviations: ABTS, 2,2'-azino-bis(3-ethylbenzothiazoline-6-sulfonic acid); ATCC, American Type Culture Collection; CLA, conjugated linoleic acid; CUPRAC, cupric-reducing antioxidant capacity; DPPH, 2,2-diphenyl-1-picrylhydrazyl; FRAP, ferric-reducing ability of plasma; ORAC, oxygen radical absorbance capacity; SOD, superoxide dismutase; TBARS, thiobarbituric acid-reactive substances; TE, Trolox equivalents; UHT, ultra-high temperature.

* Corresponding author: Dr Anthony Fardet, fax +33 4736247 55, email anthony.fardet@inra.fr 


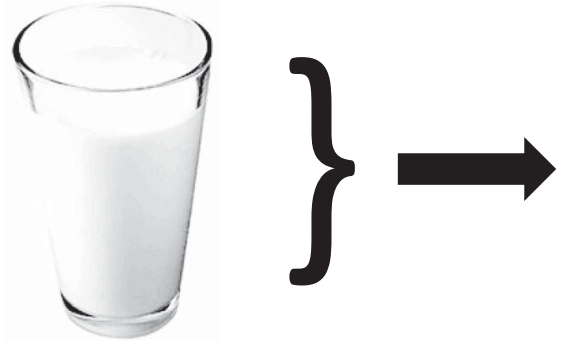

Fig. 1. Main milk antioxidants.

effect of the animal origin, genetic type (i.e. breed) ${ }^{(10)}$, feed (for example, composition, quantity, and complementation, such as the fat quality) and pasture conditions (for example, organic $v$. conventional, seasonal variations) on the antioxidant potential of milk has been repeatedly studied ${ }^{(10-23)}$.

Overall, the antioxidant potential of dairy products has been mostly studied in vitro, with very few in vivo animal and human studies. However, this is also true for other foods such as cereals, whose antioxidant potential has been extensively studied in vitro but rarely studied directly in human subjects ${ }^{(24)}$. The main issue is the important difference between in vitro and in vivo antioxidant potentials of foods, unless the in vitro potential is directly measured in digestive extracts, as demonstrated for cereal-based products ${ }^{(24,25)}$.

The objectives of the present narrative review were therefore to synthesise data on the antioxidant potential of dairy products, both in vitro and in animals and humans, as well as for each main dairy product (i.e. milks, yoghurts, fermented milks and cheeses), and to describe, when possible, the influence of processing, especially skimming, thermal treatment, fermentation, probiotic supplementation and storage, on the antioxidant potential of these foods. We chose to organise the literature results into three parts according to in vitro, animal and human studies because there is generally a relevant difference between what is measured in vitro using the typical antioxidant assays and the real in vivo antioxidant impact, which does not necessarily reflect the in vitro measurements, as we previously discussed for cereal-based foods ${ }^{(24)}$.

\section{In vitro studies}

\section{Dairy products (among food groups)}

The literature indicates that dairy products may be a source of antioxidants $^{(6)}$, notably via their protein fraction ${ }^{(7)}$. Comparing the results of one study with those of another on the basis of the
Table 1. Antioxidant potential of milk compared with that of plant-based food groups* (Ranges)

- Casein and whey

- Superoxide dismutase, catalase and glutathione peroxidase

- Coenzyme $\mathrm{Q}_{10}$

- Lactoferrin

- Vitamins E, A and $D_{3}$

- Conjugated linoleic acid

- Carotenoids and equol

- Uric acid

- Some minerals and trace elements

- Plus bioactive peptides released during digestion
Food groups

Total antioxidant capacity

\begin{tabular}{lc}
\hline Milks (UHT, commercial) & $12 \cdot 0-14 \cdot 5 \dagger$ \\
Grain-based foods & $13 \cdot 0-24 \cdot 8$ \\
Vegetable and fruit juices & $5 \cdot 6-12 \cdot 9$ \\
Spices & $4 \cdot 8-3144 \cdot 5$ \\
Dried fruits & $23 \cdot 9-85 \cdot 8$ \\
Nuts & $7 \cdot 2-179 \cdot 4$ \\
Vegetables & $1 \cdot 2-149 \cdot 2$ \\
Fruits & $1 \cdot 4-94 \cdot 6$ \\
\hline
\end{tabular}

UHT, ultra-high temperature; ORAC, oxygen radical absorbance capacity.

* Determined from the ORAC assay. Adapted from Cloetens et al. ${ }^{(4)}$ for milk products and Wu et al. ${ }^{(5)}$ for other food groups.

$\dagger$ In $\mu \mathrm{mol}$ Trolox equivalents $/ \mathrm{ml}$.

same antioxidant assay used to measure the total antioxidant capacity per g of solid food ${ }^{(5)}$ and $\mathrm{ml}$ of milk $^{(4)}$ can lead to some interesting comparisons, such as milk exhibiting a total antioxidant capacity of the same magnitude as those of grain products, fruit and vegetable juices, and some solid fruit and vegetable foods (Table 1). For example, the antioxidant capacity of commercial ultra-high temperature (UHT) cows' milk is approximately $13 \mu \mathrm{mol}$ Trolox equivalents (TE)/ml (oxygen radical absorbance capacity (ORAC) assay) ${ }^{(4)}$, while that of plant-based foods, except dried fruits and spices, is in the range of $1 \cdot 2-179 \cdot 4 \mu \mathrm{mol} \mathrm{TE} / \mathrm{g}$ (ORAC assay), with vegetables and fruits globally showing a wider range of antioxidant potentials than dairy products for a similar water content ${ }^{(5)}$. Others reported that dairy products exhibit the lowest antioxidant content, with eggs and seafood, among twenty-four food categories. For example, fruits and fruits juice - except berries have 9-fold higher antioxidant content than dairy products ${ }^{(6)}$.

Among dairy products $\mathrm{Unal}^{(26)}$ compared the antioxidant activity of different types of milk ( $n$ 14, including infant 
formula), yoghurt ( $n$ 14, including a probiotic yoghurt), fresh cream cheese $(n$ 12) and kefir $(n 6)$ purchased from a local Turkish supermarket based on the 2,2-diphenyl-1picrylhydrazyl (DPPH) assay and Fe-chelating activity. Concerning milk, the highest antioxidant activity was observed for regular whole UHT milk, which has the highest content of fat, and semi-skimmed UHT milk enriched with polyunsaturated $n-3$ fatty acids. According to the author, this could be due to the reactivity of fat-soluble antioxidants and to the fat globule membrane proteins ${ }^{(9)}$. However, three milks with the same fat content (3\%, whole, UHT) had significantly different antioxidant activities, an effect probably attributable to the various conditions of the thermal processes used by manufacturers, as stated by the authors. But other factors could have been at play, such as the season of milk production or milk source.

Semi-skimmed yoghurt exhibited significantly greater antioxidant activity than skimmed yoghurt. As expected, strawberry yoghurt has significantly higher antioxidant activity than plain yoghurt - both from the same manufacturer - which can be attributed to both the strawberries and probiotics. Indeed, an increase in antioxidant activity was detected after the addition of bifidobacteria to lactic acid bacteria in a fermented milk ${ }^{(27)}$. Creamy fresh cheeses generally have higher antioxidant activity, which can be attributed to their high levels of protein on a fresh-weight basis compared with other dairy products. Concerning the different samples of kefir, plain kefirs were different from each other in terms of antioxidant activity, which could be caused by their different compositions and processing conditions used by different manufacturers.

\section{Milk}

Antioxidants in milk. Studies on whey and deproteinised milk have shown that the major contributor to the total antioxidant capacity of whole milk is the casein fraction and that albumin is the major contributor to the total antioxidant capacity of whey protein ${ }^{(28)}$. Another study compared the trapping of free radicals in milk, milk serum (obtained by centrifugation) and whey (obtained by acidification of skimmed milk) after subjecting the samples to size exclusion chromatography ${ }^{(29)}$. As shown previously $^{(30)}$, caseins contributed the most to the antioxidant activities measured by 2,2'-azino-bis(3-ethylbenzothiazoline-6sulfonic acid) (ABTS) and ORAC assays (89\%). $\beta$-Lactoglobulin and $\alpha$-lactalbumin contributed much less to the total antioxidant capacity, and in the low-molecular-weight fractions, urate and ascorbate were identified as antioxidants. This last result was confirmed by Cloetens et al. ${ }^{(4)}$ who published a review of the antioxidant capacity of milk (breast, animal and infant milks) with a focus on measurement methods. The major antioxidant in the low-molecular-weight fractions was identified as uric acid, an important milk antioxidant, which is also in agreement with previous data ${ }^{(31)}$. Uric acid contributes $60 \%$ of the human plasma antioxidant capacity (ferric-reducing ability of plasma (FRAP) assay) $)^{(32)}$. In milk, uric acid is formed from the ruminal breakdown of microbial nucleotides ${ }^{(33,34)}$. Uric acid has both reducing and free radical-scavenging properties, which protect milk compounds from oxidative damage, and its antioxidative effect in milk is similar to that of ascorbate ${ }^{(31)}$. Other experiments have shown that the antioxidant activity of casein is mediated by its constitutive amino acids, while the antioxidant activity in whey is largely dependent on denaturation or partial hydrolysis and dominated by the free thiol groups of $\beta$-lactoglobulin ${ }^{(29)}$. Clausen et al. $^{(29)}$ also concluded that the number of major contributors in milk to the free radicalscavenging activity (ABTS and ORAC assays) is relatively low.

The study of Cekic et al. ${ }^{(35)}$ took a similar approach: the antioxidant capacity of milk was measured using two assays, cupric-reducing antioxidant capacity (CUPRAC) and ABTS, because only these assays can assess the contribution of protein to the observed total antioxidant capacity. Different types of milk were tested: organic milk; pasteurised milk; UHTprocessed fatty milk (3.0\% milk fat), low-fat milk (1.5\%) and skimmed milk (0.1\%); and homogenised milk in commercial packaging. For each milk type, three samples were analysed: defatted whole milk, a solution of milk protein and whey. Comparing the total antioxidant capacities of skimmed milk, casein, $\beta$-lactoglobulin, $\alpha$-lactalbumin, and different proteinmilk mixtures confirmed that milk proteins are responsible for a large part of the total antioxidant capacity of milk ${ }^{(35)}$.

Otherwise, $\beta$-lactoglobulin-depleted milk has been shown to possess approximately $50 \%$ less antioxidant activity than raw skimmed milk $^{(36)}$. Therefore, since $\beta$-lactoglobulin is very sensitive to thermal denaturation, dairy products should not be overheated to potentially maintain their antioxidant potential $^{(36)}$. Although $\beta$-lactoglobulin is generally considered a mild antioxidant, the authors hypothesised that it is possible that the free thiol groups in $\beta$-lactoglobulin or in other milk proteins act as a reducing agent to regenerate other antioxidants in the raw milk $^{,(36)}$. Concerning the mechanisms, Liu et al. ${ }^{(36)}$ showed that $\beta$-lactoglobulin is a mild antioxidant (<vitamin E) but the conversion of $\beta$-lactoglobulin monomers into dimers is partly responsible for the in vitro LDL protection against oxidation induced by $\mathrm{Cu}$. In addition, $\beta$-lactoglobulin substantially loses its antioxidant activity through crosslinking the thiol groups due to heating $\left(100^{\circ} \mathrm{C}\right.$ for $\left.2 \mathrm{~min}\right)$ or through carboxymethylation to block the thiol groups, with Cys-121 playing an essential role.

Cervato et al. ${ }^{(37)}$ evaluated the antioxidant properties of milk casein subunits ( $\alpha$-, $\beta$ - and $\kappa$-caseins) in liposome models. All casein subunits can inhibit the peroxidation of arachidonic acid inserted in multilamellar liposomes of dipalmitoylphosphatidylcholine, but $\alpha$-casein appears to have the greatest effect. This observation could be attributed to the Fe-chelation ability of phosphoserine residues, for which ten, five and one are present in $\alpha$-, $\beta$ - and $\kappa$-casein, respectively. Caseins appear to favour self-oxidation of $\mathrm{Fe}$ and thus inhibit lipid peroxidation $^{(38)}$. However, these authors believe that mechanisms other than simple Fe chelation are involved in the antioxidant activity of casein, indicating that caseins exhibit a variety of mechanisms in their inhibition of peroxidation, involving both the specific properties of other proteins and characteristics of caseins. Finally, milk proteins and digested peptides might contribute to protecting the endothelial cells of the digestive tract against oxidative injury by free radicals.

Power et $a l^{(39)}$ recently summarised laboratory results on antioxidant peptides, particularly those derived from milk, including their antioxidant potential measured in vitro and 
evaluated in vivo, mechanisms of action, bioavailability, potential applications and health benefits with a particular focus on ageing populations and regulatory requirements. One of the main important points is that these peptides, released during enzymic hydrolysis, are inactive when included in the 'parent' protein before digestion. The released peptides were shown to have the ability to scavenge free radicals, chelate metal ions, and/or inhibit lipid peroxidation. However, as explained by Power et $a l .{ }^{(39)}$, because of the variety of methods used to assess their antioxidant activity, data comparison from one study to another is difficult. Otherwise, the mechanisms of action of the antioxidant peptides derived from whey and casein have not been fully elucidated. Preliminary studies suggested that these mechanisms are related to the amino acid composition, sequence/structure and hydrophobicity, i.e. physico-chemical properties of the amino acids, of the peptides $^{(40)}$. In some cases, peptides derived from milk proteins have in vitro antioxidant activity similar to or even higher than that of chemical antioxidants (for example, butylated hydroxytoluene or butylated hydroxyanisole $)^{(39)}$. Further, the authors gave an overview of the antioxidative peptides derived from cows' and human milk protein following enzyme hydrolysis, including their amino acid sequences and the nature of the corresponding fragments. The authors concluded that such antioxidant peptides could find appropriate applications for specific populations such as the elderly because of the increased risk of sarcopenia and oxidative stress with ageing ${ }^{(39)}$.

The study by Woo et al. ${ }^{(41)}$ confirmed that hydrolysis of milk proteins is effective at increasing their antioxidant activity (ABTS assay). Specifically, the tryptic digest of casein showed the highest radical-scavenging activity, and the casein hydrolysates that passed through a membrane with a threshold of $3 \mathrm{kDa}$ exhibited the highest antioxidant activity. In addition, Şanlidere Aloğlu ${ }^{(42)}$ determined the antioxidant capacity of raw, pasteurised and sterilised milk before and after in vitro enzymic gastrointestinal digestion. The average values before digestion were $4.02,4.47$ and $4.18 \mathrm{mmol} \mathrm{TE} / \mathrm{g}$ for raw, pasteurised and sterilised milk, respectively (ABTS assay), which significantly increased at the end of digestion to $11.13,12.33$ and $11.88 \mathrm{mmol}$ $\mathrm{TE} / \mathrm{g}$, respectively. The main reason for this effect is that the antioxidant properties of casein and whey proteins were increased via hydrolysis in the presence of many digestive enzymes and that certain peptides released after the digestion of milk possessed an antioxidant capacity higher than that of other peptides $^{(43-45)}$. In this study, the reported values obtained via the ABTS assay were mostly higher than those previously reported by Cloetens et $a l^{(4)}$ obtained via the ORAC assay, emphasising the importance of using similar assays for relevant comparisons. While the ORAC assay is based on $\mathrm{H}$ atom transfer mechanisms and measures the oxidative degradation of a fluorescent molecule after being mixed with free radical generators, the ABTS assay measures the electron- or $\mathrm{H}$-donating properties of antioxidants, both hydrophilic and lipophilic, and is based on the conversion of ABTS to its radical cation, which is reactive towards most antioxidants. However, as most studies have been conducted in vitro, the extension to the real antioxidant potential of hydrolysed peptides in vivo will require appropriate studies in human volunteers.
If the protein fraction is the most powerful hydrophilic antioxidant in milk, the most active lipophilic antioxidant is CLA, which is uniquely found in milk, ruminant meat and eggs from chickens that have been fed CLA and is characterised by conjugated double bonds ${ }^{(7)}$. In vitro, CLA was shown to inhibit maize oil lipid peroxidation induced by $\mathrm{Cu}^{(46)}$ and to quench the stable radical DPPH ${ }^{(47)}$. In rats, CLA also protects structural lipids against free radicals and reactive oxygen species ${ }^{(48,49)}$. According to Dhiman et al. ${ }^{(50)}$ the total CLA in dairy products and milk varies from $0 \cdot 12$ to $0 \cdot 68 \%$ of the total fat. Milk from organic farms has a higher CLA content than conventional milk due to the higher content of PUFA in cows' diets in organic farming ${ }^{(51,52)}$, and Ferreiro et al. ${ }^{(53)}$ report differences of $+9 \cdot 5$ to $14.9 \%$ in favour of organic milks. Lipophilic milk antioxidants also include vitamins $\mathrm{A}, \mathrm{D}_{3}$ and $\mathrm{E}$, but milk is not a very rich source of vitamins $\mathrm{E}$ or $\mathrm{D}_{3}^{(7)}$.

In addition to a protein fraction, antioxidant peptides, uric acid, CLA and lipophilic vitamins, milk also contains bioactive secondary phenolic compounds - such as equol, a metabolite of daidzein - which are formed from plant phenolics by the bacterial flora of the cow intestine ${ }^{(54)}$. Tsen et al. ${ }^{(55)}$ analysed five commercial whole milk, four commercial semi-skimmed milk and three commercial skimmed milk samples purchased from local supermarkets in Singapore and found that the antioxidant capacity and the ability to inhibit the formation of $\mathrm{F}_{2}$-isoprostanes increased with the concentrations of phenolic compounds and equol. However, differences in the antioxidant potential were not as marked as the differences in the equol concentration, indicating that other compounds contributed to the antioxidant potential. In addition, the equol and total phenolic concentrations were positively correlated with the milk fat concentration. While fresh full-cream milk contained $47.0 \mathrm{ng} / \mathrm{ml}$ equol and $0.70 \mu \mathrm{g}$ gallic acid/g total phenolic compounds, fresh non-fat milk contained only $1.3 \mathrm{ng} / \mathrm{ml}$ and $0.04 \mu \mathrm{g}$ gallic acid $/ \mathrm{g}$, respectively. These compounds are present in higher concentrations in the lipid fraction than in the aqueous fraction of cows' milk; thus, the milk fat fraction of non-homogenised milk contained significantly higher amounts of phenolic compounds $(2 \cdot 42 v \cdot 0 \cdot 20 \mu \mathrm{g}$ gallic acid $/ \mathrm{g})$ and equol $(2 \cdot 27 v \cdot 0 \cdot 13 \mathrm{ng} / \mathrm{ml}$; $P<0.05)$ than the corresponding aqueous fraction, respectively. Therefore, skimming may potentially reduce the levels of the original equol and phenolic compounds that otherwise may depend on the feeding practice of the cow.

Influence of animal species, fat content, thermal treatments and storage. The antioxidant capacity of milk differs according to the animal source: values of $1.0,1.7,1.7,2.1$ and $2 \cdot 8 \mu \mathrm{mol} \mathrm{TE} / \mathrm{g}$ (ABTS assay) were reported for human, cows', horse, buffalo and goats' milks, respectively ${ }^{(56)}$. The authors concluded that goats' milk contains the highest concentrations of free radical scavengers than the others without giving further explanation. However, there is no doubt that the difference in antioxidant capacity according to animal origin is mainly due to the different composition of antioxidant compounds and/or the interaction of these compounds with the matrix to attenuate (by counteracting ion oxidation processes) or increase this potential. A higher antioxidant potential of goats' milk compared with cows' and donkey milk was also calculated by Simos et al. ${ }^{(57)}$. 
These authors explained that the high antioxidant capacity of goats' milk can be attributed to its richness in antioxidants, as well as the particular combination of compounds or their greater bioavailability.

According to the CUPRAC and ABTS assays, the highest total antioxidant capacity has been observed for fatty milks ${ }^{(35)}$. Skimmed milk has a $21 \%$ (CUPRAC) and 6\% (ABTS) lower total antioxidant capacity than fatty milk. According to the authors, since fat has no antioxidant activity, total antioxidant activity of milk fat can be considered to be due to antioxidants entrapped in fat during milk homogenisation before UHT sterilisation.

Further, in the study by Zulueta et al. ${ }^{(28)}$, the fat content of the milk was not correlated with the total antioxidant capacity in UHT milk, while the total antioxidant capacity of low-fat pasteurised milk was significantly lower (13624-13984 $\mu \mathrm{mol}$ TE/l; ORAC assay) than that of milk with a higher fat content (14124-14216 $\mu \mathrm{mol} \mathrm{TE} / \mathrm{l})$. Chen et al. ${ }^{(30)}$ also observed that the total antioxidant capacity (ABTS assay) in commercial cows' milk ( $3 \%$ fat) was significantly higher than in cows' milk with $0 \cdot 5-1.5 \%$ fat and skimmed milk. Such results suggested that interference with lipids and the reactivity of the lipophilic antioxidants and the fat globule membrane proteins may influence the total antioxidant capacity.

In addition to animal species and skimming, thermal treatments may also influence the milk antioxidant potential. For example, changes in potential antioxidants and pro-oxidants in pasteurised and heated skimmed milk in an oil bath at 80, 90 and $120^{\circ} \mathrm{C}$ for up to $24 \mathrm{~h}$ were measured ${ }^{(58)}$. At each heating temperature, the milk samples showed an initial increase in the pro-oxidant activity until approximately $5 \mathrm{~h}$ of thermal treatment, followed by a decrease in this activity until $24 \mathrm{~h}$; the decrease was associated with an increase in the milk antioxidant activity, especially at $90^{\circ} \mathrm{C}$ and $120^{\circ} \mathrm{C}$. Such changes were explained by both the thermal degradation of natural antioxidants and the formation of novel oxidised molecules in the early stages of the Maillard reaction. Therefore, short heat treatments may be responsible for the depletion of the overall antioxidant properties of milk. However, severe heat treatments provide recovery and even a possible increase in the antioxidant properties of milk due to the formation of brown melanoidins (Maillard reaction products). These results emphasise the important role played by the timetemperature combination of heat treatments, which could explain the apparent discrepancy with other studies showing no significant effect of temperature on the antioxidant capacity of milk.

In the previously mentioned study by Şanlidere Aloğlu ${ }^{(42)}$, the average values for raw, pasteurised $\left(72-75^{\circ} \mathrm{C}\right.$ for $\left.15-30 \mathrm{~s}\right)$ and sterilised $\left(121^{\circ} \mathrm{C}\right.$ for $\left.15 \mathrm{~min}\right)$ milks were $4.02,4.47$ and $4.18 \mathrm{mmol} \mathrm{TE} / \mathrm{g}$ (ABTS assay), respectively, with no significant difference between these values. In a study of Zulueta et al. ${ }^{\text {(28) }}$ the total antioxidant capacity of commercial UHT milks (ORAC assay) varied from $12.0(\mathrm{sD} 0.5)$ to $14.5(\mathrm{sD} 0.4) \mu \mathrm{mol} \mathrm{TE} / \mathrm{ml}$, and the capacity of pasteurised commercial milk ranged from 13.6 (sD 0.7) to 14.2 (sD 1.1) $\mu \mathrm{mol} \mathrm{TE} / \mathrm{ml}$ (ORAC assay), with no overall significant difference between the UHT and pasteurised milks. Similarly, heating the milk to $63^{\circ} \mathrm{C}$ for $1 \mathrm{~h}$ did not affect the total antioxidant capacity ${ }^{(30)}$. Therefore, Maillard reaction products resulting from heating appear to compensate for the heat-induced loss of organic antioxidant compounds.

Contrary to human breast milk, the influence of storage time on the antioxidant capacity of cows' milk has rarely been studied. The most significant study measured the antioxidant capacity (FRAP assay) of six raw cows' milk samples collected directly from a dairy and immediately cooled to $4^{\circ} \mathrm{C}$ for up to $48 \mathrm{~h}$ (i.e. refrigerated storage) ${ }^{(59)}$. The FRAP values of the raw milk significantly decreased with refrigerated storage time, i.e. $-27 \%$ upon $48 \mathrm{~h}$ of storage. According to the authors, this reduction in the total antioxidant capacity of milk can be attributed to constant and undefined interactions involving many pro- and antioxidants, but further details were not given.

Conclusions. Whole milk contains both hydrophilic (i.e. proteins and peptides, lactoferrin and antioxidant enzymes) and lipophilic antioxidants (i.e. lipophilic vitamins and CLA), and its overall total antioxidant activity will notably depend on the fat content and time-temperature combination applied (for example, Maillard products) (Table 2).

\section{Yoghurts and other fermented milks}

Antioxidant potential. The antioxidant properties of naturally fermented milk result from the presence of casein, whey proteins, peptides, amino acids, uric acid, vitamins C, E, D and A, $\beta$ carotene, and enzymic systems (SOD, catalase, and glutathione peroxidase), as well as the presence of CLA and coenzyme $Q_{10}$ and the antioxidant activity of the lactic acid bacteria or kefir culture $^{(28,60-62)}$. Fermented milks may therefore exhibit very different antioxidant potentials according to the origin of the milk and to the nature of the bacterial strain. Among different plain fermented products marketed in Poland (i.e. twelve yoghurts, twelve kefirs, two buttermilks, two cultured milks and a Turkish drink yoghurt called ayran), yoghurt and kefir were shown to have the highest antioxidant activity: the mean FRAP values were 1.19 (yoghurts), 1.03 (kefirs), 0.66 (cultured milks), 0.48 (ayran) and 0.45 (buttermilks) $\mu \mathrm{mol} \mathrm{Fe} \mathrm{F}^{2+} / \mathrm{g}^{(63)}$. The ability to scavenge DPPH radicals was $0.19 \mathrm{mmol} \mathrm{TE} / \mathrm{kg}$ for the yoghurts and $0.17 \mu \mathrm{mol} \mathrm{TE} / \mathrm{g}$ for the kefirs, followed by the buttermilks, cultured milks and ayran, for which the mean antiradical power was $0 \cdot 14,0.11$ and $0.09 \mu \mathrm{mol} \mathrm{TE} / \mathrm{g}$ (DPPH assay), respectively. The authors attributed this effect to the fortification of the yoghurt and kefir products with milk powder and/or milk proteins. In addition to a high protein content, the presence of additional probiotic strains of Lactobacillus case $i$ also positively affected the values obtained from the FRAP and DPPH assays in this study.

Influence of the mammal species. The study by Balakrishnan \& Agrawal ${ }^{(64)}$ included the preparation of a fermented milk (with Pediococcus pentosaceus from cheese) from various sources such as cows', goats' and camel milk. The scavenging activity of milk (DPPH assay, \%) after $24 \mathrm{~h}$ of fermentation was the highest with goats' milk (93 v. 54\% before fermentation), followed by camel milk (84 v. 64\% before fermentation) and cows' milk (78 v. 39\% before fermentation), illustrating an 
Table 2. Summary of the in vitro antioxidant capacity of the main dairy products

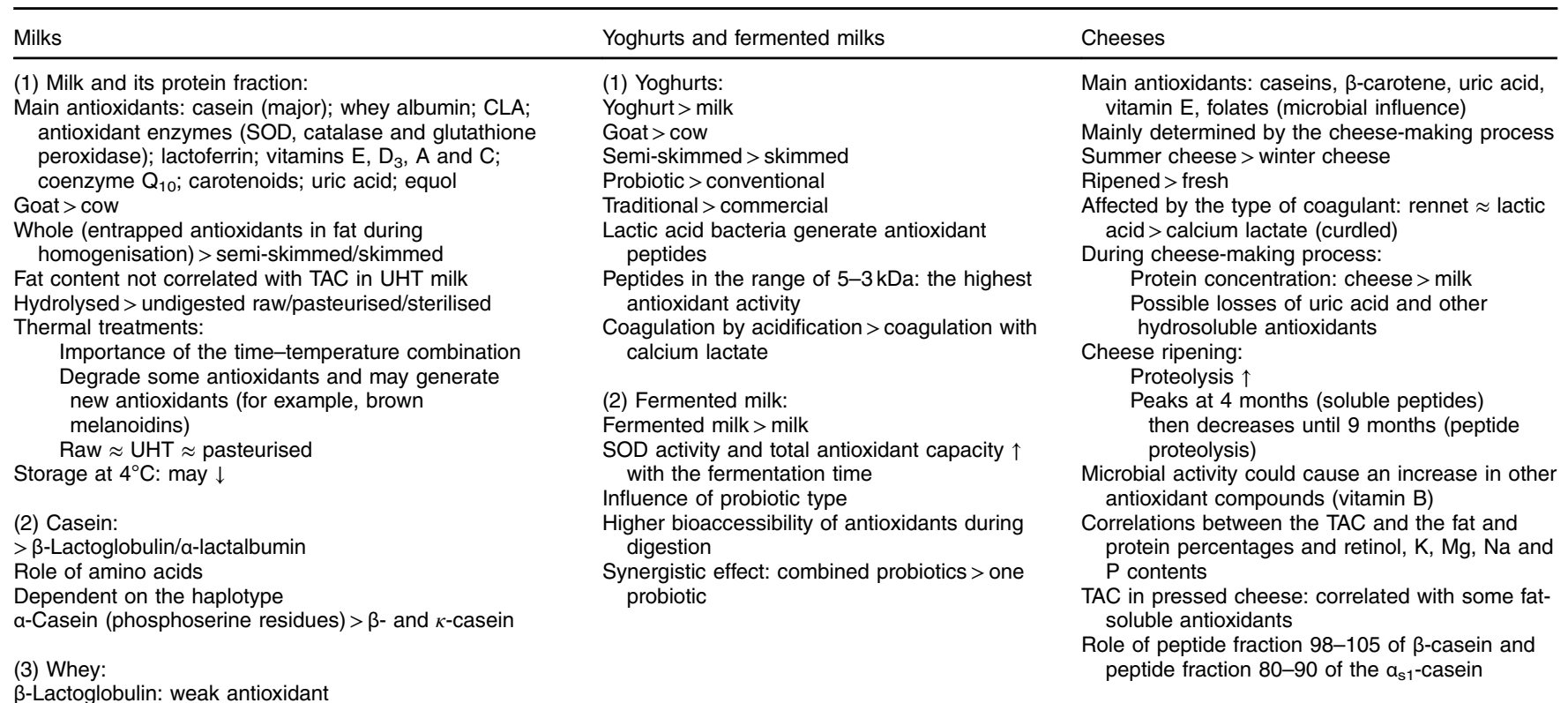

$\beta$-Lactoglobulin: weak antioxidant

Role of free thiol groups of $\beta$-lactoglobulin

Cys-121 group: essential role

(4) Antioxidant peptides:

Inactive when included in the 'parent' protein but can be released during enzymic hydrolysis

CLA, conjugated linoleic acid; SOD, superoxide dismutase; TAC, total antioxidant capacity; UHT, ultra-high temperature; $\downarrow$, decrease; $\uparrow$, increase.

important increase of up to $+39 \%$ upon fermentation. A higher antioxidant activity (Trolox equivalent antioxidant capacityABTS assay) was also observed with camel milk fermented with Lactobacillus rhamnosus PTCC 1637 compared with cows' milk ${ }^{(65)}$. This was attributed to a higher proline content in the primary structure of camel milk caseins.

Influence of casein polymorphism. Perna et al. ${ }^{(66)}$ evaluated the antioxidant activity (FRAP and ABTS assays) of a yoghurt made from milk characterised by different casein haplotypes $\left(\alpha_{\mathrm{s} 1^{-}}, \beta\right.$ - and $\kappa$-caseins) and fortified or not with chestnut and sulla honey. A haplotype is a group of alleles of different loci located on the same chromosome and usually transmitted together. The antioxidant activity of the control yoghurt was 204.43(SD 57.81) $\mu \mathrm{g}$ ascorbic acid equivalents $/ \mathrm{ml}$ based on the ABTS assay and 116.74 (SD 29.30) $\mu \mathrm{g}$ ascorbic acid equivalents $/ \mathrm{ml}$ based on the FRAP assay. The high antioxidant capacity of the yoghurt was attributed to several parameters, including the presence of different bioactive peptides from the proteolysis of milk proteins by lactic acid bacteria, the fermentation and post-acidification during storage that produce organic acids, and the possible peptide aggregation that occurs during the enzymic hydrolysis of whey protein and casein. Haplotypes BB- $\mathrm{A}^{2} \mathrm{~A}^{1}-\mathrm{AA}$ and $\mathrm{BB}-\mathrm{A}^{2} \mathrm{~A}^{1}-\mathrm{AB}$ had the highest values in both antioxidant assays compared with the control yoghurt, clearly showing that milk protein polymorphism influences the antioxidant activity of yoghurt.

Influence of fermentation and storage. When comparing a skimmed milk with the corresponding fermented milk,
Jiménez et al. ${ }^{(60)}$ observed that the fermented milk (46\%) was less effective than the skimmed milk (65\%) at inhibiting lipid peroxidation. However, both products trapped approximately $85 \%$ of free hydroxyl radicals $(\bullet \mathrm{OH})$. Moreover, based on the ABTS assay (Trolox equivalent antioxidant capacity), fermented milk had a significantly lower total antioxidant capacity of approximately $48 \%$ relative to the skimmed milk after 6 min of measurement but had a capacity of $+62 \%$ after $24 \mathrm{~h}$ of measurement. No explanation was proposed for this unexpected effect.

The proteolytic systems of lactic acid bacteria are the main way to generate bioactive peptides, including both free radicalscavenging antioxidant activity and angiotensin-converting enzyme-inhibiting activity, during fermentation of the milk ${ }^{(67)}$. Evaluating the antioxidant properties of a skimmed milk fermented with Lactobacillus delbrueckii ssp. bulgaricus LB340 revealed that among four peptide fractions of 10-5, 5-3, 3-1 and $<1.0 \mathrm{kDa}$, those in the range of $5-3 \mathrm{kDa}$ exhibited the highest antioxidant activity (66\%, DPPH assay), which was not significantly different from that of the $3-1 \mathrm{kDa}$ peptide fraction $(64 \%)^{(68)}$. The DPPH free radical-scavenging effect of the $<1.0 \mathrm{kDa}$ peptide fraction reached $55 \%$. Furthermore, the antioxidant activity was correlated with the molecular weight from 0 to $5 \mathrm{kDa}$. However, considering the mucus layer in the small intestine, which has a thickness of 100-150 $\mu \mathrm{m}$, molecular filters with an exclusion molecular weight of $0 \cdot 6-0.8 \mathrm{kDa}$ were used, and due to the peptidase in the intestinal epithelial cells, the authors suggested that the antioxidant activity of the peptide fraction less than $1.0 \mathrm{kDa}$ might represent that of fermentation better in vivo ${ }^{(69),(68)}$. Qian et al. ${ }^{(68)}$ reported results 
that agreed with those of Peng et al. ${ }^{(70)}$ showing that the $0 \cdot 1-2 \cdot 8 \mathrm{kDa}$ fraction from whey protein isolation had the strongest free radical-scavenging capacity.

In a commercial fermented milk, researchers tried to identify the peptides included in the most active (angiotensin-converting enzyme and antioxidant activities) protein fractions isolated by reverse-phase HPLC-MS ${ }^{(71)}$. Among several potentially active peptides, the $\beta$-casein peptide KVLPVPQ may possess antioxidant activity. Of the isolated fractions, the highest antioxidant activity was found in a fraction where seven of the eight peptides identified contained at least one proline residue, and six of them had more than two proline residues. Therefore, according to the authors, 'the high content of proline peptides could determine the antioxidant activity found in this fraction, ${ }^{,(71)}$.

In a study by Aloğlu \& Oner ${ }^{(72)}$, the physico-chemical and microbiological properties of commercial and traditional yoghurts were determined during 4 weeks of storage, as well as the proteolytic activity and antioxidant activities (DPPH and ABTS assays) of peptides derived from hydrolysis. The antioxidant activity of water-soluble extracts of traditional yoghurt was higher than that of commercial yoghurt, reflecting differences in the chemical and microbiological properties. The physico-chemical and microbiological properties of traditional yoghurts generally do not meet the commercial standards. During storage for up to 4 weeks $\left(4^{\circ} \mathrm{C}\right)$, the average values increased from 7.7 to $8.7 \mathrm{mmol} \mathrm{TE} / \mathrm{g}$ for the commercial yoghurts and from $10 \cdot 1$ to $13.2 \mathrm{mmol} / \mathrm{g}$ for the traditional yoghurt (ABTS assay). The presence and position of the amino acids tryptophan, tyrosine and methionine in the peptides were believed to be responsible for the antioxidant activity. Finally, if the initial total antioxidant activity of the yoghurts was low, the activity of the peptides released from the HPLC fractions was 10- to 200-fold higher.

Concerning the influence of cold storage $\left(4^{\circ} \mathrm{C}\right)$, an increased antioxidant activity of fermented cows' and camel milks was observed for up to $21 \mathrm{~d}$ due to an increase in proteolytic activity, but the increase primarily occurred between 14 and $21 \mathrm{~d}^{(65)}$. Thus, the increase in proteolysis during storage increases the release of antioxidant peptides even more than fermentation.

Influence of the probiotic strain. The influence of the strain of probiotic on the antioxidant potential of fermented milks has been studied much more than the previous parameters. Most of these studies were based on the release of antioxidant peptides by different probiotics.

Studies have coherently demonstrated a correlation between an increased degree of proteolysis and the antioxidant potential. In the most recent study, Solieri et al. ${ }^{(73)}$ isolated non-starter lactobacilli from different cheeses because of their proteolytic activity and their ability to produce fermented milk enriched with angiotensin-converting enzyme and antioxidant peptides. Thirty-four strains of Lactobacillus from Parmesan cheese and five strains from Pecorino Siciliano (or Canestrato) were screened for their ability to hydrolyse milk proteins, and two strains from Parmesan, Lactobacillus casei PRA205 and Lactobacillus rhamnosus PRA331, were selected to inoculate sterile cows' milk. The milk fermented with Lactobacillus casei PRA205 had a higher radical-scavenging activity (1.2 $(\mathrm{SD} 0 \cdot 0) \mathrm{mmol} \mathrm{TE} / \mathrm{ml}$ ) than the milk fermented with
Lactobacillus rhamnosus $(0 \cdot 9(\mathrm{sD} 0 \cdot 1) \mathrm{mmol} \mathrm{TE} / \mathrm{ml})$ (ABTS assay). In addition to this effect, the increases in proteolytic and radical-scavenging activities measured during the fermentation of milk for $120 \mathrm{~h}$ were clearly correlated, confirming the important role of peptides in the antioxidant activity of fermented milks. Ramesh et al. ${ }^{(74)}$ studied the influence of different lactobacilli strains ( $n$ 19) from ten different species on the antioxidant capacity of the whey fraction of skimmed milk. The radical-trapping antioxidant activity ranged from 0.12 to $0.49 \mathrm{mmol}$ TE/l (ABTS assay), confirming the low antioxidant capacity of the whey fraction. In agreement with previous results, the antioxidant and proteolytic activities of seven strains (i.e. Lactobacillus delbrueckii ssp. bulgaricus NCDC08, Lactobacillus plantarum NCDC25, Lactobacillus casei ssp. casei NCDC17, Lactobacillus rhamnosus NCDC24, Lactobacillus paracasei ssp. paracasei NCDC63, Lactobacillus fermentum NCDC141 and Lactobacillus belveticus NCDC288) were positively correlated. After the hydrolysis of casein with cell-free extracts from these seven strains, a significant increase in antioxidant activity was observed for Lactobacillus rhamnosus NCDC24, Lactobacillus casei ssp. casei NCDC17 and Lactobacillus paracasei ssp. paracasei NCDC63. For these three strains, low-molecular-weight peptides $(<3.0 \mathrm{kDa})$ represented $60-70 \%$ of the total antioxidant activity. Virtanen et al. ${ }^{(75)}$ studied the production of antioxidant activity (ABTS assay and lipid peroxidation) during fermentation with commonly used lactic acid ferments. Sterilised skimmed milk $\left(120^{\circ} \mathrm{C}\right.$ for $\left.20 \mathrm{~min}\right)$ was fermented with twenty-five different strains of lactic acid bacteria, and the six with the highest antioxidant activity were selected. The whey fraction was isolated from each fermented milk for measurement of its antioxidant capacity. In both assays, the strains Leuconostoc mesenteroides ssp. cremoris, Lactobacillus jensenii (American Type Culture Collection (ATCC) 25258) and Lactobacillus acidophilus (ATCC 4356) exhibited the highest antioxidant activity. The development of antioxidant activity was correlated with proteolysis for four strains. Additionally, the highest hydrophobic amino acid content and proportion of peptides in the molecular mass range of 4-20 kDa were found within fermentates with the highest antioxidant capacity, while the other fermentates mostly contained large polypeptides and compounds below $4 \mathrm{kDa}$. The development of antioxidant activity was therefore clearly specific for the strain. Interestingly, the authors concluded that 'The development of radical scavengers was more connected to the simultaneous development of proteolysis whereas lipid peroxidation inhibitory activity was related to bacterial growth, ${ }^{,(75)}$. Similarly, Sah et al. ${ }^{(76)}$ evaluated the effect of the probiotics Lactobacillus acidophilus (ATCC 4356), Lactobacillus casei (ATCC 393) and Lactobacillus paracasei ssp. paracasei (ATCC BAA52) on the antioxidant and antimutagenic activity of peptides extracted from yoghurt. Again, the degree of proteolysis by these probiotics was highly correlated with the antioxidant and anti-mutagenic activities of peptides, and the released peptides showed high antioxidant activity in the DPPH assay. The yoghurt containing the three probiotic strains together had the highest degree of hydrolysis and the highest antioxidant activity, emphasising a potential synergistic effect.

Other studies have generally compared the respective antioxidant potential of adding different probiotic strains and 
emphasised the synergistic action of combined strains compared with only one strain. A sterilised milk (unspecified thermal conditions) with $3 \cdot 2 \%$ fat was fermented with different microbial cultures, including a symbiotic culture of Lactobacillus delbrueckii ssp. bulgaricus and Streptococcus thermophilus and monocultures of Lactobacillus acidophilus, Lactobacillus casei and Bifidobacterium bifidus ${ }^{(77)}$. For all cultures, the antioxidant activity of the fermented products was increased compared with non-fermented milk. The highest antioxidant activity was observed with Lactobacillus acidophilus, which neutralised 55\% of the free radicals, and the lowest activity was observed with Lactobacillus delbrueckii ssp. bulgaricus and Streptococcus thermophilus (45\%). The authors suggested that the increased antioxidant activity was not only due to released peptides but also to free amino acids, enzymes and various other compounds. Similarly, $\operatorname{Lim}^{(78)}$ evaluated the antioxidant properties of yoghurt fermented with lactic acid bacteria from pickled cabbage. Yoghurt fermented with Lactobacillus acidophilus PC16 had the highest antioxidant activity (DPPH assay) compared with yoghurt fermented with Lactobacillus casei PC05. Conversely, the ability to scavenge the superoxide anion and the activity of the enzyme SOD were significantly higher in yoghurt fermented with Lactobacillus casei PC05 compared with yoghurt fermented with Lactobacillus acidophilus PC16. Upon cold storage, there was no significant difference in the antioxidant activities of these yoghurts. In the study by Aleksandrova et al. ${ }^{(79)}$ four strains of Lactobacillus delbrueckii were selected based on their high proteolytic activity. All of the strains belonged to the subspecies lactis and bulgaricus and were used in combination with a commercial strain for yoghurt LBB BY D4 (LB Bulgaricum plc) to produce a yoghurt-type dairy product (from skimmed milk). The in vivo antioxidant activity caused by the peptides obtained during the fermentation of milk proteins was analysed in living yeast cells. The main results showed that the antioxidant capacity towards reactive oxygen species in the yeast cells was higher with the combination of strains than with only the commercial strain and that the different strains exhibited different antioxidant capacities. Osuntoki \& Korie $^{(80)}$ isolated lactobacilli from five native Nigerian fermented foods to ferment whey fractions from skimmed milk and measure their antioxidant activity (DPPH assay and lipid peroxidation inhibition assay). All the whey fractions had antioxidant activity, and the five isolates of lactobacilli with the highest activity were selected (Lactobacillus brevis, Lactobacillus fermentum, Lactobacillus plantarum, Lactobacillus casei and Lactobacillus delbrueckii). The whey fractions were then fermented for $24 \mathrm{~h}$ with the selected microorganisms. The antioxidant activity increased during the $24 \mathrm{~h}$ in all cases, but differently according to the strain; however, with Lactobacillus delbrueckii, the activity increased less and plateaued at $4 \mathrm{~h}$. The authors further concluded that the fermented milk may serve as a vehicle for probiotic lactobacilli from non-dairy sources. Finally, Parrella et $a l .{ }^{(81)}$ studied the antioxidant capacity (ORAC and FRAP assays) of nine different samples of fresh skimmed (derived directly from the udder of the cow), pasteurised and UHT milks before and after fermentation with several lactobacilli, individually, and in combination with the yeast Saccharomyces boulardii. As expected, all fermented milk samples had greater antioxidant activity than the unfermented milk, with the effect being significant only for fresh milk. The co-incubation of the lactobacilli with yeast led to greater antioxidant activity, especially for fresh milk.

Specific case of kefir. Kefir is a fermented milk drink prepared by inoculating cows', goats' or sheep's milk with kefir grains. The kefir grains initiating the fermentation are a combination of lactic acid bacteria and yeasts in a matrix of proteins, lipids and sugars. This symbiotic culture forms 'grains' that resemble cauliflower. Lactobacillus species are always present in kefir grains. Kefir appeared to have higher antioxidant potential but reduced glutathione peroxidase activity compared with the milk from which it has been fermented ${ }^{(82)}$. In addition, the free radical-scavenging activity of the plain kefir increased by $10 \%$ with prolonged fermentation from 16 to over $24 \mathrm{~h}^{(82)}$. However, no difference was observed in the ferrous ion-chelating ability or SOD activity. Liu et al. ${ }^{(61)}$ explained that "The antioxidative activity of kefirs may be attributed to their proton-donating ability, their reducing power and SOD-like activity as evidenced through DPPH and superoxide radical scavenging and lipid peroxidative inhibition results'. Concerning the different types of kefir, Kesenkas et al. ${ }^{(83)}$ compared full-fat and skimmed milkbased kefir inoculated with grains with a commercial culture using four different antioxidant assays and found that the fat content and the nature of the fermentation did not affect the antioxidant properties of the kefir. These results suggest that kefirs may be relevant candidates for useful and natural antioxidant supplements in the human diet.

Influence of in vitro digestion. Gagnon et al. ${ }^{(84)}$ evaluated the bioaccessibility of antioxidants during the in vitro digestion of a reconstituted skimmed milk that had been fermented with five selected strains of Bifidobacterium longum ssp. longum. Contrary to previously mentioned studies, the milk fermented with these five strains did not have an initial antioxidant capacity (ORAC assay) higher than unfermented milk. However, higher bioaccessibility of the antioxidants in the fermented milk was observed during digestion. Surprisingly, strains with a low survival rate - compared with the strain showing the best survival rate - in fermented milk were shown to deliver more bioaccessible antioxidants during in vitro dynamic digestion. Therefore, the milk fermented with various strains of Bifidobacterium longum ssp. longum provided bioaccessible antioxidants during digestion, notably at the colonic level, that could prevent the excessive generation of oxidative compounds (i.e. free radicals by microbiota) within the digestive $\operatorname{tract}^{(85)}$.

Conclusions. Yoghurt exhibits higher antioxidant potential than milk, notably due to the presence of probiotics generating antioxidant peptides. This is also true for other fermented milks but antioxidant activity greatly depends on the type and number of added probiotics (Table 2).

\section{Cheeses}

Influence of cheese processing and composition. The most recent study dealt with the factors affecting the antioxidant capacity (ABTS assay) of 224 different cheese samples 
(of known composition) prepared using sixteen varied mixtures of milk from cows, ewes and goats during two manufacturing seasons (winter and summer) and over 6 months of ripening ${ }^{(86)}$. Several correlation analyses were performed. First, the total antioxidant capacity was significantly correlated with the seasonality of manufacturing and the time of ripening but not with the animal species providing the milk. The antioxidant capacity was higher in summer than in winter because of the higher Trolox equivalent antioxidant capacity values observed at month 0 (except for winter goats' cheese) and mainly at 1 and 2 months in the summer cheeses. This difference resulted from the lower hydrophobic:hydrophilic peptide ratios in summer than in winter cheeses, especially after the first month of ripening, indicating strong proteolysis. Second, significant correlations between the total antioxidant capacity and the retinol content $(r$ 0.399), fat percentage $(r$ 0.308), protein percentage ( $r$ 0.366), K content $(r 0.385), \mathrm{Mg}$ content $(r 0.312)$, Na content $(r 0.432)$ and $\mathrm{P}$ content $(r 0.272)$ were reported, in agreement with previous results ${ }^{(87)}$. However, the positive correlations between minerals and the total antioxidant capacity are probably due to the significant positive correlation between the protein content (because the total antioxidant capacity is primarily associated with caseins) and these minerals. Based on these results, the authors generated a model to predict the antioxidant capacity in unknown cheeses of different compositions and ripening times ${ }^{(86)}$

Therefore, because cheeses exhibit a very high diversity of composition and structure (matrix characteristics), their antioxidant potential could be modulated. Lucas et $a l^{(88)}$ studied the respective effects of the composition of milk and processing on the antioxidant potential of five varieties of French cheese, i.e. Abondance ( $n 10$ cheeses, including both winter and summer cheeses), Tomme de Savoie ( $n$ 10, including both winter and summer cheeses), Cantalet ( $n$ 12, only winter cheeses) and Salers ( $n$ 6, only summer cheeses) from cows' milk, and Rocamadour ( $n$ 15, including both winter and summer cheeses) from goats' milk. The compositional variability of the cheese in terms of fatty acids, $\beta$-carotene, xanthophylls and vitamin E depended mainly on the animal species composition of the milk, i.e. goat $v$. cow. The total antioxidant capacity of the cheeses ranged from 6.35 to $24.3 \mathrm{mmol} \mathrm{Fe}{ }^{2+} / \mathrm{g}$ DM (FRAP assay). As expected, a higher total antioxidant capacity was measured in goats' milk. In this study, statistical analyses showed no significant correlation between the milk composition and total antioxidant capacity. Furthermore, none of the antioxidant compounds analysed in this study was found to be positively or negatively correlated with the total antioxidant capacity, which can be explained either by the synergistic action of several compounds or by the action of antioxidant compounds not analysed in this study.

Pattorn \& Hongsprabhas ${ }^{(89)}$ studied the influence of coagulation methods - commonly used to prepare milk protein curds from skimmed milk - on the antioxidant activity of milk protein curds and powders. Precipitation by calcium lactate (curd), coagulation by lactic acid and rennetting of skimmed milk proteins were tested. Curdled milk from precipitation had the densest network (as observed via scanning electron microscopy) and the lowest antioxidant capacity, i.e. 0.27
(ORAC assay) and 0.05 (ABTS assay) $\mu \mathrm{mol} \mathrm{TE} / \mathrm{mg}$ protein, compared with the other dairy preparations $(0.52-0.57$ and $0.42-0.44 \mu \mathrm{mol} \mathrm{TE} / \mathrm{mg}$ protein, respectively; $P<0.05)$. Furthermore, trypsin hydrolysis for $30 \mathrm{~min}$ increased the antioxidant capacity of all products to $0 \cdot 85-1 \cdot 11$ (ORAC assay) and $1 \cdot 17-1 \cdot 19$ (ABTS assay) $\mu \mathrm{mol} \mathrm{TE} / \mathrm{mg}$ protein, regardless of the coagulant used. In terms of practical applications, these results showed that the milk powder precipitated by calcium lactate could be used as a dietary protein source that would provide antioxidant peptides during tryptic digestion. As written by the authors, the 'study also suggests that the hydrolysates of milk proteins with reasonable antioxidant capacity could be achieved with milk powder prepared from mixed protein coagulated by calcium lactate, lactic acid or rennet, and then hydrolyzed by trypsin', adding that 'this is important for developing countries with majority of the population suffering from lactose intolerance, i.e., having milk surplus, yet lacking the capacity of fractionation of milk proteins into individual proteins such as casein $\beta$, casein $\kappa, \beta$-lactoglobulin and $\alpha$-lactalbumin,(89).

Gupta et al. ${ }^{(90)}$ aimed to isolate and characterise antioxidant peptides $(<3 \mathrm{kDa}$, isolated by reverse-phase HPLC and analysed by liquid chromatography-tandem MS, ABTS assay) in Cheddar-type cheese inoculated with Lactobacillus casei ssp. casei 300. The authors identified two peptides from milk proteins: VKEAMAPK $(m / z$ 872.5048), corresponding to the 98-105 fraction of $\beta$-casein, and HIQKEDVPSER $(\mathrm{m} / z$ 1336.7034), corresponding to the 80-90 fraction of $\alpha_{\mathrm{s} 1}$-casein (i.e. protein fragment composed of amino acids initially at positions 98-105 and 80-90 of the linear protein sequence). Interestingly, the antioxidant activity of the VKEAMAPK peptide was comparable with that of commercial antioxidants such as butylated hydroxyanisole, tert-butylhydroquinone and ferulic acid, but the activity of the HIQKEDVPSER peptide was lower. Therefore, this proteolytic strain of lactic acid bacteria can be used to further improve the antioxidant potential of Cheddar cheese via the release of antioxidant peptides.

Influence of ripening time. A recent study investigated the proteolysis and total antioxidant capacity of proteins from white brined cheese prepared from overheated goats' milk and ripened for $50 \mathrm{~d}^{(91)}$. Proteolysis after cheese ripening induced increases in the antioxidant capacity of both the water-soluble and water-insoluble protein fractions. For example, after $30 \mathrm{~d}$ of ripening, the total antioxidant capacity of the water-soluble fraction increased by $12 \%$. After that period, a more intensive increase was observed, and cheese ripened for $50 \mathrm{~d}$ had a total antioxidant capacity that was $56 \%$ higher than that of fresh cheese. This study showed that both the content and nature of $\mathrm{N}$ components are essential for the antioxidant capacity. Similarly, Parvin et al. ${ }^{(92)}$ showed that the antioxidant activity of Bangladesh Gouda and Dhaka cheeses increases with ripening time (up to 2 months).

Gupta et al. ${ }^{(93)}$ evaluated changes in the antioxidant properties (ABTS and DPPH assays, scavenging activity and superoxide anion) of aqueous extracts of Cheddar cheese (inoculated with Lactobacillus casei ssp. casei 300 and Lactobacillus paracasei subsp. paracasei 22) at different stages of ripening 
but on a longer time scale than in previous studies. As previously reported, the antioxidant activity first increased to a peak at 4 months and then decreased until 9 months of ripening. The changes in the antioxidant activity were linked to the rate of formation of soluble antioxidant peptides upon proteolysis until 4 months. The decrease observed after 4-5 months of ripening indicates that the antioxidant peptides were not resistant to the continuing proteolysis.

The antioxidant capacity (ABTS assay) of water-soluble extracts of Parmigiano Reggiano cheese at different ageing times (up to 41 months) was also studied (ABTS assay) ${ }^{(94)}$. The antioxidant capacity was determined after simulated in vitro gastrointestinal digestion of these extracts. Contrary to previous studies, the antioxidant capacity in water extracts of Parmigiano Reggiano cheese was unaffected by the ripening time and gastrointestinal digestion. Using liquid chromatography-electrospray ionisation-MS, the authors also showed that the antioxidant capacity of the water-soluble extracts was mostly due to free amino acids, mainly tyrosine, methionine and tryptophan, and secondarily to antioxidant peptides, but only minimally.

It is difficult to make generalisations from these studies but it seems that the antioxidant capacity of cheese increases upon ripening to an optimum due to peptide release then decreases due to peptide hydrolysis; this effect and the optimum antioxidant capacity probably depend on cheese type and ripening time.

Influence of in vitro digestion. In the study by Abadia-Garcia et $a l{ }^{(95)}$, the viability of probiotic micro-organisms added to cottage cheese in simulated gastrointestinal digestion, the release of peptides with potential antioxidant activity (DPPH and ABTS assays) and their antimicrobial effect on Listeria monocytogenes were evaluated. Cottage cheese was prepared with Lactobacillus casei, Lactobacillus rhamnosus GG, and the commercial mix YO-MIX ${ }^{\mathrm{TM}} 205$ incorporated, in addition to a control without added probiotics. Higher numbers of potentially bioactive peptides were observed in the cheeses with added probiotics. During storage for $28 \mathrm{~d}\left(8^{\circ} \mathrm{C}\right)$, the antioxidant activity of the soluble cheese extracts determined by the DPPH assay increased, but the one determined by the ABTS assay did not (no difference between the control and the cheeses containing probiotics). Based on the DPPH assay, the increase was strongest with the commercial mix and lower with the control and probiotic Lactobacillus rhamnosus GG. This increase was attributed to the proteolytic activity of the micro-organisms that released antioxidant bioactive peptides. The different behaviour depending on the antioxidant assay used may be due to the different structure of the radical, which can react differently depending on the peptides present in the aqueous extract. According to the authors, these results indicated that the "probiotic microorganisms exhibited a significant level of survival in simulated gastric juice when delivered in a cottage cheese ${ }^{, 95)}$. In contrast, 'environmental simulated conditions of the duodenum, where bile salts and pancreatic juices are secreted, had more influence on bacterial viability, ${ }^{(95)}$.

Conclusions. As with yoghurt and fermented milks, cheese also contains antioxidants, especially casein, but with less variety resulting from losses during the cheese-making process. Its total antioxidant activity is mainly determined by the process used, notably that which concentrates the protein fraction leading to higher antioxidant potential than milk. During ripening, proteolysis combined with possible microbial activity may increase this potential (Table 2).

\section{Animal studies}

\section{Milk and milk proteins}

The influence of milk and its derived proteins on several physiological functions has been studied in either rats or mice. However, the designs and objectives of each study have greatly differed.

In the most recent study, male control and anaemic weaned rats were administered for 30 and 50 d cows' or goats' skimmed milk-based diets with either a normal $(45 \mathrm{mg} / \mathrm{kg})$ or overloaded $\left(450 \mathrm{mg} / \mathrm{kg}\right.$ ) Fe content to induce chronic Fe overload ${ }^{(96)}$. Fe overload is notably known for potentially increasing oxidative stress. Anaemia by Fe deficiency had no effect on the antioxidant enzymes (catalase and glutathione peroxidase) or lipid peroxidation in the liver, brain and erythrocytes. During chronic Fe repletion, the activity of SOD was largely higher in the group fed cows' milk compared with the group consuming goats' milk. Otherwise, the catalase and glutathione peroxidase activities were only slightly changed in rats fed a cows' milk-based diet, suggesting that the level of both enzymes are sufficient to neutralise the expected high production of free radicals. In addition, a cows' milk-based diet led to higher levels of lipid peroxidation (thiobarbituric acid-reactive substances; TBARS) compared with a goats' milk-based diet, which was directly correlated with the increase in the SOD activity. The increase in lipid peroxidation reflects the neutralisation of the hydroxyl radical $(\bullet \mathrm{OH})$, a very reactive free radical, derived from dismutation of the superoxide anion $\left(\mathrm{O}_{2}^{--}\right)$. Finally, because goats' milk had a positive effect on antioxidant defence, even in conditions of Fe overload, and limited lipid peroxidation, the authors proposed that goats' milk should be recommended for those affected by nutritional Fe-deficiency anaemia, especially for individuals consuming oral Fe supplements. Another study was also based on the fact that Fe supplementation may induce lipid peroxidation and then contribute to the induction of intestinal lesions ${ }^{(97)}$. This mechanism is notably observed in intense sports, where athletes frequently use a higher complementation of Fe with unknown effects. Since milk proteins have in vitro antioxidant properties, Zunquin et $a l .{ }^{(97)}$ believed that they could thwart potential secondary effects of Fe on oxidative stress in rats. After $30 \mathrm{~d}$, compared with untrained rats, all exercise-trained rats exhibited an increase in antioxidant enzyme activities (SOD and glutathione peroxidase) and in Fe concentrations in their colonic mucosa and liver. All these parameters were significantly reduced by supplementation with casein milk protein. In addition to these effects, free casein and casein bound to $\mathrm{Fe}$ were found to significantly reduce Fe-induced lipid peroxidation (TBARS formation). Therefore, regarding anaemia and the consumption of oral Fe supplements, dietary milk protein 
supplementation could partly prevent the occurrence of deleterious effects to tissue induced by Fe overload.

Two other studies evaluated the influence of dairy products on the antioxidant status of obese rats. Indeed, angiotensinconverting enzyme inhibitors in dairy products may suppress the oxidative and inflammatory stress associated with obesity. To test this hypothesis, Zemel \& Sun ${ }^{(98)}$ carried out a study for 3 weeks in adipocyte fatty acid-binding protein-agouti transgenic mice fed obesogenic diets, including a diet rich in $\mathrm{Ca}$ and a diet rich in dairy products (skimmed milk powder: $400 \mathrm{~g} / \mathrm{kg}$ ). Compared with the basal diet, the production of reactive oxygen species in adipose tissue and the levels of NADPH oxidase mRNA and plasma malondialdehydes were reduced with the Ca-rich diet $(P<0.05)$. The effect was even more pronounced with the dairy-rich diet $(P<0.001)$. These results led the authors to conclude that dietary $\mathrm{Ca}$ and dairy products inhibit oxidative stress in a mouse model of diet-induced obesity and oxidative stress. They proposed that dietary Ca-induced suppression of circulating 1 1 ,25-dihydroxycholecalciferol may be responsible for the Ca-induced suppression of oxidative stress. This hypothesis is based on the ability of $1 \alpha, 25$-dihydroxycholecalciferol to stimulate inflammatory cytokine production, as shown in an adipocyte and macrophage co-culture ${ }^{(99)}$. Concerning milk proteins, casein and, more particularly, whey peptides were shown to reduce plasma, brain, heart and liver lipoperoxide contents and to increase liver glutathione and ATP contents in rats fed an obesogenic diet for 4 weeks and then casein- or hydrolysed milk-serum-restricted diets ${ }^{(100)}$. The authors proposed potential mechanisms for the higher efficacy of a whey peptidebased diet compared with casein in terms of an improved antioxidant status: (1) the smaller whey peptides are easily digested and absorbed, better promoting protein turnover for the synthesis of antioxidant enzymes; and (2) whey peptides supply $\beta$-alanine, which is fundamental for the synthesis of carnosine, an efficient antioxidant, as well as taurine, another antioxidant.

Considering the protective role of dietary Ca and other dairy components against oxidative and inflammatory stress, which otherwise accelerate the process of ageing, Bruckbauer \& Zemel $^{(101)}$ evaluated the life-long effects of dietary Ca from both non-dairy and dairy (milk, non-fat, dry) sources on the lifespan of aP2-agouti transgenic (model of diet-induced obesity) and wild-type mice and on lifespan-related biomarkers, including some antioxidant biomarkers, until death. The age-related increase in reactive oxygen species production was significantly blunted in the high-Ca and milk-diet groups compared with the control group, with the effect being significant for the milk diet only after 78 weeks. Concerning SOD3 gene expression in the soleus, the wild-type mice showed increased levels in the milk-diet group, while no diet effect was found in the transgenic mice. Concerning SOD3 gene expression and enzyme activity in the liver, an overall increase in enzyme activity in the liver of mice in the milk-diet group compared with those in the high-Ca and control groups was observed, with no significant difference in gene expression. Therefore, although these effects had no influence on the maximum lifespan, they suppressed early mortality ${ }^{(101)}$.
Finally, because diets containing evaporated milk or skimmed milk powder are particularly efficient at inducing $\mathrm{Cu}$ deficiency ${ }^{(102,103)}$, the study by Lynch \& Strain ${ }^{(104)}$ investigated the effects of different diets based on skimmed milk powder, casein or whey on the $\mathrm{Cu}$ status of control and $\mathrm{Cu}$-deficient rats. The tissue $\mathrm{Cu}$ levels, Cu-Zn SOD activity and cytochrome $c$ oxidase activity were significantly lower in control animals fed skimmed milk powder compared with those fed casein, while lactoserum-fed rats showed intermediate values for these measurements linked to $\mathrm{Cu}$ status. In addition, the hepatic activities of glutathione reductase and Se-dependent glutathione peroxidase were significantly higher in rats fed the skimmed milk powder diet. However, all of the diets had significant effects on the hepatic levels of TBARS.

\section{Fermented milks}

In vitro fermented milks globally exhibit higher antioxidant potential than unfermented milks due to the release of antioxidant peptides. Only three studies have investigated this potential effect in either ageing mice ${ }^{(105)}$, weanling rats ${ }^{(106)}$ or healthy normal rats ${ }^{(107)}$.

According to Rohit et $a l .{ }^{(105)}$ the role of probiotics in the modulation of redox homeostasis during ageing remains unclear. Their study was conducted in male mice aged 16 months consuming a basic diet, supplemented or not with skimmed milk or milk fermented with probiotic Lactobacillus fermentum MTCC 5898. After 2 months on these diets, the antioxidant enzymes (SOD, catalase and glutathione peroxidase) in the probiotic group had significantly increased activities in the liver compared with those in the unfermented milk group. In erythrocytes, significantly increased activity was only observed for glutathione peroxidase. No significant difference between the control and unfermented skimmed milk groups was observed. Overall, these results clearly indicated an improved free radical clearance system following Lactobacillus fermentum MTCC 5898 administration.

In the following study, the effects of skimmed milk and cultured milk supplementation on peroxidative stress in the brains of weanling rats were investigated ${ }^{(106)}$. First, compared with the control brains, the TBARS concentrations were reduced in milk-supplemented animals. In addition, the brain SOD levels were significantly lower in the milk-supplemented animals, and the TBARS concentrations were positively correlated with SOD activity in the control animal brains. Otherwise, no significant differences in the brain glutathione $S$-transferase levels between the control, milk and cultured milk groups were reported. Therefore, both skimmed milk and cultured milk have antiperoxidative actions in vivo. In conclusion, the authors proposed that the milk protein rather than the lactobacilli was responsible for reducing lipid peroxidative stress in rat brains.

This next study examining the effect of whey from skimmed cows' milk fermented with bifidobacteria and lactic acid bacteria on the antioxidant enzymes in rats for 6 weeks essentially confirmed previous results ${ }^{(107)}$. The rats consumed a reference control diet, a diet with whey from unfermented milk and a diet with whey from skimmed milk inoculated with Bifidobacterium longum, Lactobacillus acidophilus or 
Streptococcus salivarius ssp. thermophilus. The superoxide oxidase activity of blood cells and the liver catalase activity were increased by the whey from fermented milk, regardless of the nature of the strains, compared with the control diet. In addition, the activity of glutathione peroxidase in blood cells was higher with whey fermented with Lactobacillus acidophilus compared with the control diet. However, although no significant differences were observed between any of the diets in terms of plasma levels of TBARS and $\alpha$-tocopherol, the lipoprotein fractions with a density less than $1.063 \mathrm{~g} / \mathrm{ml}$ and prepared from rats fed the whey fermented with Bifidobacterium longum and Lactobacillus acidophilus were resistant to oxidative stress compared with the control diet. Overall, although some of the peroxidative changes induced by the cultured products were also observed with the non-fermented whey, the latter was less effective at increasing the activity of antioxidant enzymes than the cultured whey-based diets.

\section{Cheeses}

The effect of cheeses on the antioxidant status has been investigated only in rats. In the first study, thirty different Italian cheeses from three groups, i.e. 'furmai da mut', 'caprino' and 'stracchino' ( $n$ 10/group, different producer for all thirty cheeses), were added to the diets of thirty groups of four normal rats $^{(108)}$. Some of the cheeses from each group either significantly improved or deteriorated the oxidative balance, as measured through an oxidative index (plasma hydroperoxides/total cholesterol plasma level) and oxidative balance risk index ((oxidative index x total cholesterol plasma level)/plasma antioxidant ratio), but there was no significant effect when considering the pooled effect of the ten cheeses within each group.

The other study aimed at evaluating the effects of unripened cheese supplements on the antioxidant status in hypercholesterolaemic rats fed a high-cholesterol diet with or without $5 \%$ unripened cheese for 6 weeks ${ }^{(109)}$. The unripened cheesebased diet led to increases in plasma retinol and $\alpha$-tocopherol of 40.5 and $39.2 \%$, respectively, and to an increased resistance to oxidative stress of leucocyte DNA of $52.3 \%$ compared with the hypercholesterolaemic group without cheese. Furthermore, the significant increase in the peroxidation of plasma lipids in the hypercholesterolaemic group was reversed to its basal level in the presence of unripened cheese. The authors concluded that unripened cheese supplementation could exert significant health benefits in hypercholesterolaemic subjects, including improved antioxidant effects.

\section{Conclusions}

Animal studies investigating the antioxidant potential of dairy products are quite rare, and all have been carried out in different murine models. Goats' milk, casein milk proteins, a dairyrich diet, whey peptides, a milk-based diet and skimmed milk powder were all shown to reduce various markers of oxidative stress in different models of increased oxidative stress.

Concerning fermented milks, they all exhibited antioxidant activities in murine models, probably with a higher potential than unfermented milk, but this has to be confirmed. Finally, for cheese, results are inconclusive and paradoxical.

\section{Human studies}

In 2013, Cloetens et $a l^{(4)}$ reported that in adults, many intervention studies have been conducted on the effect of dairy products in the diet but very few have focused on the effect of milk on antioxidant systems. Indeed, only twelve relevant studies were identified, and among them one epidemiological study hypothesising the pro-oxidative effect of galactose.

\section{Dairy products}

Two studies by Zemel and collaborators ${ }^{(110,111)}$ investigated the effect of dairy products or a dairy-based diet on the antioxidant status in overweight and obese subjects. The basis of their first study was that oxidative and inflammatory stress are elevated in obesity and are further augmented in the metabolic syndrome ${ }^{(111)}$. Therefore, forty overweight and obese adults with the metabolic syndrome were administered for 12 weeks a low-dairy $(<0.5$ dairy servings/d and $<600 \mathrm{mg} \mathrm{Ca} / \mathrm{d})$ or adequate-dairy ( $>3.5$ dairy product servings/d, $\geq 1200 \mathrm{mg} \mathrm{Ca} / \mathrm{d}$ ) weight-maintenance diet. The low-dairy diet had no effect on oxidative markers, i.e. plasma malondialdehyde (nmol/l) and oxidised LDL $(\mathrm{ng} / \mathrm{ml})$. Conversely, the adequate-dairy diet decreased malondialdehyde and oxidised LDL on day 7 (35 and $11 \%$, respectively; $P<0.01$ ), with further decreases by the twelfth week. Otherwise, the adequate-dairy diet exerted significantly greater effects on oxidative biomarkers in the obese subjects compared with the overweight subjects. These results showed that adequate intake of dairy products significantly attenuates oxidative as well as inflammatory stress in the metabolic syndrome, partly explaining the protective effect of dairy products against this metabolic dysregulation ${ }^{(112-114)}$.

Zemel et $a l .{ }^{(110)}, 1$ year before, compared dairy products with soya in the form of smoothies on oxidative and inflammatory stress in overweight and obese subjects. Smoothies were administered three times per $\mathrm{d}$ throughout a $28 \mathrm{~d}$ treatment period according to a blinded, randomised, cross-over design comparing dairy product- with soya-supplemented isoenergetic diets. The dairy product-based diet led to a significant reduction of oxidative stress, with a reduction of $22 \%$ plasma malondialdehyde and $12 \%$ plasma 8 -isoprostane- $\mathrm{F}_{2 \alpha}(P<0.0005)$. The soya-based diet had no effect. Higher effects were reported at $28 \mathrm{~d}$ than at $7 \mathrm{~d}$. However, contrary to their above-mentioned study, there were no significant differences between the overweight and obese subjects.

\section{Milk and milk-derived proteins}

Studies concerning milk and its derived protein fraction also greatly differ in their designs and objectives.

The most recent study was an epidemiological cohort study carried out in Swedish women and men ${ }^{(115)}$. Compared with a low milk intake $(<1$ glass/d) and a high intake of fruit/ vegetables ( $\geq 5$ servings/d), the risk (hazard ratio, adjusted) for all-cause mortality was 2.79 (95\% CI $2.42,3.21)$ in women consuming at least three glasses of milk/d and less than one serving/d of fruit/vegetables and 1.60 (95\% CI 1.40, 1.82) in women consuming the same amount of milk but at least five servings/d of fruit/vegetables. In men, the same comparisons 
resulted in risks of 1.31 (95\% CI 1.14, 1.51) and 1.07 (95\% CI $0 \cdot 97,1 \cdot 18)$, respectively. Based on studies carried out on murine models, the authors hypothesised that the milk pro-oxidant galactose (component of lactose) may be one of the main causes of these observed effects ${ }^{(116-118)}$, with the increase in oxidative stress specifically associated with a lower life expectancy in animals $^{(119)}$ and with chronic diseases in humans ${ }^{(120,121)}$. Therefore, this study did not support a protective antioxidant effect of milk, as previously shown by the same researchers reporting higher concentrations of oxidative stress in human urine (levels of 8 -iso- $\mathrm{PGF}_{2 \alpha}$ ) associated with a high consumption of milk ${ }^{(122)}$. However, milk is a complex matrix containing not only lactose but also numerous antioxidant constituents that rebalance the overall antioxidant potential (for example, casein, lactoferrin, bioactive peptides released during digestion, and antioxidant enzymes). The above-mentioned studies in animals attest to the antioxidant protective effect of milk and dairy products in general. Excess simple sugars promote an increase in oxidative stress $^{(123)}$. Therefore, one can regret that Michaelsson et $a l^{(122)}$ did not adjust the hazard ratio on total or added simple sugars, which often reflect an adherence to a Western (energyrich and low level of fruits and vegetables) diet also rich in pro-oxidants. This may also means that heavy milk consumers more generally adhere to a Western pro-oxidant diet. Therefore, the comparison of 'milk $(<1$ glass/d $)+$ fruits/vegetables ( $\geq 5$ servings/d)' with 'milk ( $\geq 3$ glasses/d) + fruits/vegetables ( $<1$ serving/d)' is not the most common scenario, and the hazard ratio was no more significant when comparing, for example, 'milk (1-1.9 glasses/d) + fruits/vegetables (2-4.9 servings/d)' with 'milk ( $<1$ glass/d) + fruits/vegetables ( $\geq 5$ servings/d)'. In the same study, beyond milk the increased consumption of fermented milk or yoghurts per d was shown to be associated with an improved antioxidant status in humans. More generally, the study by Michaëlsson et $a l^{(122)}$ showed the importance of a global approach to studying milk consumption in relation to the type of complex diet in which it is consumed. The pro-oxidative effect is probably attributed to the complex diet rather than to a single food product within the diet, for example, in a Western energy-rich diet.

Based on the fact that cows' milk proteins may be a novel source of antioxidants that could be used in a nutritional strategy to maintain muscle mass during ageing, Power-Grant et $a .^{(124)}$ studied the antioxidant potential of different milk-based protein matrices (i.e. intact milk protein concentrate and two hydrolysate whey protein concentrates with 32 and $45 \%$ degrees of hydrolysis) before and after simulated gastrointestinal digestion and determined whether the plasma antioxidant capacity was similarly modified in vivo following acute ingestion (after $3 \mathrm{~h}$ ) of these matrices in healthy 50- to 70 -year-old women. The in vitro digestion increased the antioxidant capacity by approximately $35 \%$ for all matrices (from 24365 to $42592 \mu \mathrm{mol} \mathrm{TE} / 100 \mathrm{~g}$ dry weight, $P<0 \cdot 05$; ORAC assay). In vivo milk-based proteins increased the fasting plasma antioxidant capacity by approximately $23 \%$ for all matrices (from 10952 to $13519 \mu \mathrm{mol} \mathrm{TE} / 100 \mathrm{~g}$ dry weight, $P<0 \cdot 05$; ORAC assay). Thus, there was an association between the changes in the ORAC-based measurement of the antioxidant capacities both in vitro and in vivo.
In the study by Hunter et $a l^{(125)}$ forty-two healthy smokers consumed lemonade or control milk twice daily for 2 or 6 weeks, respectively. Based on several antioxidant biomarkers (serum uric acid and plasma ORAC, FRAP, protein carbonyls and vitamin C), milk appeared neutral with no significant differences compared with lemonade.

Zavorsky et al. ${ }^{(126)}$ studied the consumption by healthy subjects of whey protein-based bars that had undergone highpressure treatment. High-pressure treatment of whey protein may increase the digestibility and bioavailability of cysteine. Each group ( $n$ 3) ingested 15,30 or $45 \mathrm{~g} / \mathrm{d}$ of pressurised whey protein in the morning in bar format for $14 \mathrm{~d}$. The significantly increased level of glutathione, a major cellular antioxidant in humans, in cells was linearly related with the amount of consumed whey protein. Thus, pressurised whey protein supplementation of $45 \mathrm{~g} / \mathrm{d}$ for 2 weeks increased lymphocyte glutathione by $24 \%$.

Campbell et al. ${ }^{(127)}$ also studied the effect of milk proteins in healthy adult men (double-blind cross-over meal-challenge study). Based on the anti-atherogenic potential of soya isoflavones, their main objective was to test whether soya ( $85 \mathrm{mg}$ of aglycone isoflavones, treatment) or $40 \mathrm{~g}$ of milk protein ( $0 \mathrm{mg}$ of aglycone isoflavones, control) in combination with a high-fat meal can modify postprandial, atherogenicassociated events and biomarkers of oxidative stress (i.e. ex vivo Cu-induced LDL oxidation), inflammation and thrombosis. There was no significant difference between the treatments, suggesting an equivalent effect of soya isoflavones and milk proteins on LDL oxidation.

Önning et al. ${ }^{(128)}$ studied the effects of different milks (oat, soya and cows') on the antioxidant status (ABTS assay), among other variables, in twenty-four healthy males and females. Half of the subjects consumed $0 \cdot 75-1$ litres/d of oat and soya milk for 4 weeks each, and the other half consumed oat and cows' milk during two periods of 4 weeks. Again, no consistent change in the antioxidant status was observed after consumption, regardless of the diet followed.

Finally, milk may be a relevant source of Se, which is a potential antioxidant and an antioxidant enzyme cofactor. To further explore the effects of Se in milk, Ravn-Haren et al. ${ }^{(129)}$ carried out a randomised, double-blind, cross-over study with a 4 x 1-week design, in which young healthy men supplemented their usual diet with either Se-enriched milk, Se-enriched yeast, selenate or placebo (non-enriched milk). The milk was prepared by giving cows a high dose of selenomethionine ${ }^{(130)}$, and most of the Se in milk was protein bound. All sources of Se increased the serum Se levels after supplementation for 1 week, but the effect of the two organic forms was more pronounced than that of selenate. Conversely, thrombocyte glutathione peroxidase was increased during periods in which the subjects were supplemented with selenate but not during those in which they received Se-enriched yeast or milk. No effect was found on the resistance of plasma lipids to oxidation or on the activities of glutathione peroxidase, glutathione reductase and glutathione $S$-transferase as measured in erythrocytes. Several other variables measured in plasma or leucocytes were also not affected. No specific effects of milk enriched with Se were demonstrated with respect to the Se-enriched yeast, leading the authors to conclude 
that insufficient information was available to form solid conclusions regarding the in vivo antioxidant potential of milk.

\section{Fermented milk and probiotic yoghurt}

As we previously reported in the present review, fermented milk and probiotics may repress oxidative stress, notably due to the production of antioxidant peptides. Several studies have tested the effect of fermented and probiotic milk and yoghurt on the antioxidant status in diabetic or healthy young/adult subjects and in pregnant women.

Ejtahed $e t a l .{ }^{(131)}$ assessed the effects of conventional $v$. probiotic yoghurt on the antioxidant status of sixty-four patients with diabetes (type 2, aged 30-60 years). For 6 weeks, the test patients consumed $300 \mathrm{~g} / \mathrm{d}$ of probiotic yoghurt containing Lactobacillus acidophilus La5 and Bifidobacterium lactis Bb12, and the control patients consumed $300 \mathrm{~g} / \mathrm{d}$ of plain yoghurt. The probiotic yoghurt significantly increased erythrocyte SOD and blood glutathione peroxidase activities and the total antioxidant status compared with the control plain yoghurt. In addition, in the two groups, the serum concentration of malondialdehydes significantly decreased compared with baseline. However, erythrocyte catalase activity did not change compared with the basal value in the two groups. According to the authors, probiotic yoghurt is a functional food that can exert antioxidant effects.

This next study was based on the observation that pregnancy is associated with elevated levels of oxidative stress and was therefore designed (randomised, single-blind, controlled) to determine the effects of daily consumption of probiotic yoghurt on oxidative stress among Iranian adult pregnant women (18-30 years $)^{(132)}$. The study was carried out for 9 weeks with subjects consuming $200 \mathrm{~g} / \mathrm{d}$ of either conventional yoghurt or probiotic yoghurt, using several antioxidant biomarkers. Contrary to plain conventional yoghurt, probiotic-containing yoghurt led to significant changes in the plasma glutathione level $(+67.9 \mu \mathrm{mol} / \mathrm{l})$, serum 8-oxo-7,8-dihydroguanine level $(-74.3 \mathrm{ng} / \mathrm{ml})$, erythrocyte glutathione peroxidase activity $(+163 \mathrm{nmol} / \mathrm{min}$ per $\mathrm{ml})$ and glutathione reductase $(+323 \mathrm{nmol} /$ min per $\mathrm{ml}$ ) activity. However, while conventional yoghurt decreased the total antioxidant capacity, probiotic yoghurt had no significant effect. Despite such differences, between-group differences were only significant for erythrocyte glutathione reductase activity.

The following studies were all carried out in healthy subjects. The effects of probiotic and conventional yoghurts on antioxidant parameters were tested in young healthy women (22-29 years old) consuming $100 \mathrm{~g} / \mathrm{d}$ of these yoghurts for 2 weeks, followed by $200 \mathrm{~g} / \mathrm{d}$ for an additional 2 weeks ${ }^{(133)}$. The consumption of each yoghurt led to significant decrease in the average antioxidant concentrations (vitamin E, lycopene and zeaxanthin) during the 4 weeks. However, the average concentrations of lutein, $\beta$-carotene, albumin, uric acid and bilirubin decreased significantly only in the probiotic group. Such alterations consequently led to a significant reduction in the average total antioxidant capacity during the 4 weeks for both yoghurts. Additionally, the mean plasma levels of malondialdehyde and conjugated dienes increased significantly in the probiotic and control groups. The SOD activity remained essentially constant in both groups throughout the study, and the mean activities of glutathione peroxidase and catalase significantly decreased only in the probiotic group. However, although several parameters changed significantly during the study, no significant differences were observed between the two investigated groups.

The authors suggested that regular intake of lactic acid bacteria results in antioxidant depletion, antioxidant enzyme modulation, and enhanced oxidative stress and cautiously concluded that these results indicate a possible negative influence of probiotics and conventional yoghurt on plasma levels of antioxidants and antioxidant parameters. The significant increase in the concentrations of malondialdehyde and conjugated dienes and the reduction of the plasma antioxidant concentrations 'might be the result of enhanced oxidative stress caused by the stimulation of the immune system induced by both probiotic bacteria and conventional yoghurt strains, ${ }^{\text {,(133) }}$. In contrast, in the cross-over and double-blind South Korean study by Nam et $a l .{ }^{(134)}$ performed in twenty-six healthy volunteers consuming a fermented milk or placebo two times/d for 2 weeks, the consumption of fermented milk significantly increased the total antioxidant status of the volunteers and decreased the level of TBARS compared with the period before the consumption of fermented milk.

The objective of another study was to develop a goats' milk fermented with the human lactobacilli strain, Lactobacillus fermentum ME-3, and to test its effect on oxidative stress markers in the blood and urine of healthy human subjects (35-65 years old $)^{(135)}$. Two groups consumed either goats' milk or fermented goats' milk groups $(150 \mathrm{~g} / \mathrm{d})$ for $21 \mathrm{~d}$. Fermentation had significant additive effects by increasing the systemic total antioxidant activity and total antioxidant status and decreasing the baseline value of diene conjugates in the lipoprotein fraction, oxidised LDL, glutathione redox ratio and 8-isoprostanes after $21 \mathrm{~d}$. This pilot study therefore confirmed that the probiotic Lactobacillus fermentum ME-3 can survive in the gastrointestinal tract and exhibits antioxidative effects in human subjects.

\section{Conclusions}

Overall, milk-based diets tested in human subjects have no significant effects on antioxidant biomarkers. However, two studies showed antioxidant effects of dairy products, intact milk protein concentrate and hydrolysed whey proteins. Concerning fermented milks, most studies showed improved antioxidant status in human subjects compared with unfermented milks. Finally, whey protein consumption was shown to be correlated with glutathione levels.

\section{Conclusions}

Overall, the antioxidant potential of dairy products is of the same order of magnitude as that of some food groups such as grain-based foods, vegetables and fruit juices and some intact vegetable and fruit species (Table 1). A synthesis of the in vitro antioxidant capacity of the main dairy products is presented in Table 2. Among all dairy products, cheeses would present the 
highest antioxidant potential, probably because of their higher protein content and the fermentation process. This seems to be confirmed in the study by Carlsen et al. ${ }^{(6)}$ who reported, among more than 3100 foods, that cheeses tend to have on average a slightly higher antioxidant capacity than milks and yoghurts. However, the use of different antioxidant assays (for example, ABTS, FRAP and ORAC) renders dairy product antioxidant values difficult to compare from one study to another.

In humans, the few available studies - together with in vitro and animal studies - suggest that the antioxidant potential of dairy products, rather than milk alone, may contribute to an improved antioxidant status in humans and subsequently to their reported protective effects against some chronic diseases such as obesity, the metabolic syndrome, type 2 diabetes and some CVD. For yoghurts and fermented milks, most in vivo studies support the in vitro findings showing an improved antioxidant status (increased levels of antioxidant enzymes, overall antioxidant capacity, and resistance of LDL to oxidation and decreased levels of malondialdehydes/TBARS) in mice, rats and human subjects after consumption of fermented milk/probiotic yoghurts compared with unfermented milk. However, some studies in human subjects showed no significant effect on antioxidant status, and one study showed increased oxidative stress. However, it is important to keep in mind that an in vivo increase in antioxidant enzymes can also be interpreted as a defence system compensated by increased levels of antioxidant enzymes against a potential pro-oxidant effect of some milk fractions.

The present literature review therefore clearly illustrates the lack of human studies exploring the antioxidant potential of dairy products. Therefore, there is still insufficient information from which to draw solid conclusions regarding the antioxidant potential of milk in humans, especially considering the contradictory results of some studies. In addition, the available in vivo studies greatly differ in terms of their objectives and designs and the health status of the animal or human subjects and, as such, cannot be used to reach solid conclusions.

\section{Acknowledgements}

The present review received no specific grant from any funding agency in the commercial or not-for-profit sectors.

A. F. drafted the manuscript. E. R. provided critical revision of the manuscript. Both authors contributed to and approved the final version of the manuscript.

A. F. and E. R. declare no conflicts of interest.

\section{References}

1. Benzie IFF (2003) Evolution of dietary antioxidants. Comp Biochem Physiol A Mol Integr Physiol 136, 113-126.

2. Ames BN, Shigenaga MK \& Hagen TM (1993) Oxidants, antioxidants, and the degenerative diseases of aging. Proc Natl Acad Sci U S A 90, 7915-7922.

3. Serafini M \& Peluso I (2016) Functional foods for health: the interrelated antioxidant and anti-inflammatory role of fruits, vegetables, herbs, spices and cocoa in humans. Curr Pharm Des 22, 6701-6715.

4. Cloetens L, Panee J \& Akesson B (2013) The antioxidant capacity of milk - the application of different methods in vitro and in vivo. Cell Mol Biol 59, 43-57.
5. Wu X, Beecher GR, Holden JM, et al. (2004) Lipophilic and hydrophilic antioxidant capacities of common foods in the United States. J Agric Food Chem 52, 4026-4037.

6. Carlsen MH, Halvorsen BL, Holte K, et al. (2010) The total antioxidant content of more than 3100 foods, beverages, spices, herbs and supplements used worldwide. NutrJ9, 3.

7. Grażyna C, Hanna C, Adam A, et al. (2017) Natural antioxidants in milk and dairy products. Int J Dairy Technol 70, 165-178.

8. Fardet A \& Boirie Y (2014) Associations between food and beverage groups and major diet-related chronic diseases: an exhaustive review of pooled/meta-analyses and systematic reviews. Nutr Rev 72, 741-762.

9. Lindmark-Månsson H \& Åkesson B (2000) Antioxidative factors in milk. BrJ Nutr 84, 103-110.

10. Perna A, Intaglietta I, Simonetti A, et al. (2013) Effect of genetic type and casein haplotype on antioxidant activity of yoghurts during storage. J Dairy Sci 96, 3435-3441.

11. Kusche D, Kuhnt K, Ruebesam K, et al. (2015) Fatty acid profiles and antioxidants of organic and conventional milk from low- and high-input systems during outdoor period. J Sci Food Agric 95, 529-539.

12. Kuhnen S, Moacyr JR, Mayer JK, et al. (2014) Phenolic content and ferric reducing-antioxidant power of cow's milk produced in different pasture-based production systems in southern Brazil. J Sci Food Agric 94, 3110-3117.

13. Aguiar SC, Cottica SM, Boeing JS, et al. (2014) Effect of feeding phenolic compounds from propolis extracts to dairy cows on milk production, milk fatty acid composition, and the antioxidant capacity of milk. Anim Feed Sci Technol 193, 148-154.

14. Castillo C, Pereira V, Abuelo Á, et al. (2013) Effect of supplementation with antioxidants on the quality of bovine milk and meat production. Scientific WorldJournal 2013, 616098.

15. Krzyzewski J, Strzalkowska N, Bagnicka E, et al. (2012) Effects of antioxidants in fat contained in bulky forages on cow's milk quality. Zywnosc-Nauka Technologia Jakosc 19, 35-45.

16. La Terra S, Marino VM, Manenti M, et al. (2010) Increasing pasture intakes enhances polyunsaturated fatty acids and lipophilic antioxidants in plasma and milk of dairy cows fed total mix ration. Dairy Sci Technol 90, 687-698.

17. Zhuo C \& Wang Z (2011) Effects of dietary selenium yeast on antioxidant properties and milk fatty acid composition of dairy cow. Chin J Anim Sci 47, 56-59.

18. Aoki N, Furukawa S, Sato K, et al. (2010) Supplementation of the diet of dairy cows with trehalose results in milk with low lipid peroxide and high antioxidant content. J Dairy Sci 93, 4189-4195.

19. Pattono D, Battaglini LM, Barberio A, et al. (2009) Presence of synthetic antioxidants in organic and conventional milk. Food Chem 115, 285-289.

20. Butler G, Nielsen JH, Slots T, et al. (2008) Fatty acid and fatsoluble antioxidant concentrations in milk from high- and low-input conventional and organic systems: seasonal variation. J Sci Food Agric 88, 1431-1441.

21. Puppel K, Nalecz-Tarwacka T, Kuczynska B, et al. (2013) Effect of different fat supplements on the antioxidant capacity of cow's milk. Archiv Fur Tierzucht-Arch Anim Breed 56, 178-190.

22. Branciari R, Ranucci D, Trabalza-Marinucci M, et al. (2015) Evaluation of the antioxidant properties and oxidative stability of Pecorino cheese made from the raw milk of ewes fed Rosmarinus officinalis L. leaves. Int J Food Sci Technol 50, 558-565. 
23. Perna A, Intaglietta I, Simonetti A, et al. (2015) Effect of genetic type on antioxidant activity of Caciocavallo cheese during ripening. J Dairy Sci 98, 3690-3694.

24. Fardet A, Rock E \& Rémésy C (2008) Is the in vitro antioxidant potential of whole-grain cereals and cereal products well reflected in vivo? J Cereal Sci $\mathbf{4 8}$, 258-276.

25. Pérez-Jiménez J \& Saura-Calixto F (2005) Literature data may underestimate the actual antioxidant capacity of cereals. J Agric Food Chem 53, 5036-5040.

26. Unal G (2012) Antioxidant activity of commercial dairy products. Agro Food Industry Hi-Tech 23, 39-42.

27. Wang Y-C, Yu R-C \& Chou C-C (2006) Antioxidative activities of soymilk fermented with lactic acid bacteria and bifidobacteria. Food Microbiol 23, 128-135.

28. Zulueta A, Maurizi A, Frigola A, et al. (2009) Antioxidant capacity of cow milk, whey and deproteinized milk. Int Dairy J 19, 380-385.

29. Clausen MR, Skibsted LH \& Stagsted J (2009) Characterization of major radical scavenger species in cow milk through size exclusion chromatography and functional assays. J Agric Food Chem 57, 2912-2919.

30. Chen J, Lindmark-Mansson H, Gorton L, et al. (2003) Antioxidant capacity of cow milk as assayed by spectrophotometric and amperometric methods. Int Dairy $J \mathbf{1 3}$, 927-935.

31. Østdal H, Andersen HJ \& Nielsen JH (2000) Antioxidative activity of urate in cow milk. J Agric Food Chem 48, 5588-5592.

32. Benzie IFF \& Strain JJ (1996) The ferric reducing ability of plasma (FRAP) as a measure of "antioxidant power": the FRAP assay. Anal Biochem 239, 70-76.

33. Giesecke D, Ehrentreich L, Stangassinger M, et al. (1994) Mammary and renal excretion of purine metabolites in relation to energy-intake and milk-yield in dairy-cows. J Dairy Sci 77, 2376-2381.

34. Johnson LM, Harrison JH \& Riley RE (1998) Estimation of the flow of microbial nitrogen to the duodenum using urinary uric acid or allantoin. J Dairy Sci 81, 2408-2420.

35. Cekic SD, Demir A, Baskan KS, et al. (2015) Determination of total antioxidant capacity of milk by CUPRAC and ABTS methods with separate characterisation of milk protein fractions. J Dairy Res 82, 177-184.

36. Liu HC, Chen WL \& Mao SJT (2007) Antioxidant nature of cow milk $\beta$-lactoglobulin. J Dairy Sci $90,547-555$.

37. Cervato G, Cazzola R \& Cestaro B (1999) Studies on the antioxidant activity of milk caseins. Int J Food Sci Nutr 50, 291-296.

38. Maubois J \& Leonil J (1989) Peptide du lait à activité biologique (Milk peptide with biological activity). Lait 69, 245-269.

39. Power O, Jakeman P \& FitzGerald RJ (2013) Antioxidative peptides: enzymatic production, in vitro and in vivo antioxidant activity and potential applications of milkderived antioxidative peptides. Amino Acids 44, 797-820.

40. Chen H-M, Muramoto K, Yamauchi F, et al. (1998) Antioxidative properties of histidine-containing peptides designed from peptide fragments found in the digests of a soybean protein. J Agric Food Chem 46, 49-53.

41. Woo S-H, Jhoo J-W \& Kim G-Y (2009) Antioxidant activity of low molecular peptides derived from milk protein. Korean J Food Sci Anim Resour 29, 633-639.

42. Şanlidere Aloğlu H (2013) The effect of various heat treatments on the antioxidant capacity of milk before and after simulated gastrointestinal digestion. Int $J$ Dairy Technol 66, 170-174.
43. Hernández-Ledesma B, Dávalos A, Bartolomé B, et al. (2005) Preparation of antioxidant enzymatic hydrolysates from $\alpha$-lactalbumin and $\beta$-lactoglobulin. Identification of active peptides by HPLC-MS/MS. I Agric Food Chem 53, 588-593.

44. Park EY, Morimae M, Matsumura Y, et al. (2008) Antioxidant activity of some protein hydrolysates and their fractions with different isoelectric points. J Agric Food Chem 56, 9246-9251.

45. Mandalari G, Adel-Patient $\mathrm{K}$, Barkholt V, et al. (2009) In vitro digestibility of $\beta$-casein and $\beta$-lactoglobulin under simulated human gastric and duodenal conditions: a multi-laboratory evaluation. Regul Toxicol Pharmacol 55, 372-381.

46. Badr El-Din NK \& Omaye ST (2007) Concentrationdependent antioxidant activities of conjugated linoleic acid and $\alpha$-tocopherol in corn oil. J Sci Food Agric 87, $2715-2720$.

47. Fagali N \& Catala A (2008) Antioxidant activity of conjugated linoleic acid isomers, linoleic acid and its methyl ester determined by photoemission and DPPH center dot techniques. Biophys Chem 137, 56-62.

48. Palacios A, Piergiacomi V \& Catala A (2003) Antioxidant effect of conjugated linoleic acid and vitamin A during nonenzymatic lipid peroxidation of rat liver microsomes and mitochondria. Mol Cell Biochem 250, 107-113.

49. Kim HK, Kim SR, Ahn JY, et al. (2005) Dietary conjugated linoleic acid reduces lipid peroxidation by increasing oxidative stability in rats. $J$ Nutr Sci Vitaminol 51, 8-15.

50. Dhiman TR, Nam SH \& Ure AL (2005) Factors affecting conjugated linoleic acid content in milk and meat. Crit Rev Food Sci Nutr 45, 463-482.

51. Bergamo P, Fedele E, Iannibelli L, et al. (2003) Fat-soluble vitamin contents and fatty acid composition in organic and conventional Italian dairy products. Food Chem 82, 625-631.

52. Rehberger B, Bisig W, Eberhard P, et al. (2007) Assessment of processing technologies which may improve the nutritional composition of dairy products - overview of progress. In Improving Sustainability in Organic and Low Input Food Production Systems. Proceedings of the 3rd International Congress of the European Integrated Project "Quality Low Input Food" (QLIF), 20-23 March 2007, pp. 384-387, University of Hohenheim, Germany.

53. Ferreiro T, Gayoso L \& Rodriguez-Otero JL (2015) Milk phospholipids: organic milk and milk rich in conjugated linoleic acid compared with conventional milk. J Dairy Sci 98, 9-14.

54. Mustonen EA, Tuori M, Saastamoinen I, et al. (2009) Equol in milk of dairy cows is derived from forage legumes such as red clover. Br J Nutr 102, 1552-1556.

55. Tsen SY, Siew J, Lau EKL, et al. (2014) Cow's milk as a dietary source of equol and phenolic antioxidants: differential distribution in the milk aqueous and lipid fractions. Dairy Sci Technol 94, 625-632.

56. Oner Z, Sanlidere-Aloglu H \& Dedebaş T (2011) Determination of antioxidant capacity in milk from various animals and humans. Milchwissenschaft-Milk Sci Int 66, 133-135.

57. Simos Y, Metsios A, Verginadis I, et al. (2011) Antioxidant and anti-platelet properties of milk from goat, donkey and cow: an in vitro, ex vivo and in vivo study. Int Dairy $J$ 21, 901-906.

58. Calligaris S, Manzocco L, Anese M, et al. (2004) Effect of heat-treatment on the antioxidant and pro-oxidant activity of milk. Int Dairy J 14, 421-427. 
59. Amamcharla JK \& Metzger LE (2014) Modification of the ferric reducing antioxidant power (FRAP) assay to determine the susceptibility of raw milk to oxidation. Int Dairy J 34, 177-179.

60. Jiménez AM, Antonia Murcia M, Parras P, et al. (2008) On the importance of adequately choosing the ingredients of yoghurt and enriched milk for their antioxidant activity. Int J Food Sci Technol 43, 1464-1473.

61. Liu JR, Lin YY, Chen MJ, et al. (2005) Antioxidative activities of kefir. Asian-Australas J Anim Sci 18, 567-573.

62. Pihlanto A (2006) Antioxidative peptides derived from milk proteins. Int Dairy J 16, 1306-1314.

63. Najgebauer-Lejko D \& Sady M (2015) Estimation of the antioxidant activity of the commercially available fermented milks. Acta Sci Pol Technol Aliment 14, 387-396.

64. Balakrishnan G \& Agrawal R (2014) Antioxidant activity and fatty acid profile of fermented milk prepared by Pediococcus pentosaceus. J Food Sci Technol 51, 4138-4142.

65. Moslehishad M, Ehsani MR, Salami M, et al. (2013) The comparative assessment of ACE-inhibitory and antioxidant activities of peptide fractions obtained from fermented camel and cow milk by Lactobacillus rhamnosus PTCC 1637. Int Dairy J 29, 82-87.

66. Perna A, Intaglietta I, Simonetti A, et al. (2014) Antioxidant activity of yoghurt made from milk characterized by different casein haplotypes and fortified with chestnut and sulla honeys. J Dairy Sci 97, 6662-6670.

67. Gobbetti M, Minervini F \& Rizzello CG (2004) Angiotensin I-converting-enzyme-inhibitory and antimicrobial bioactive peptides. Int J Dairy Technol 57, 173-188.

68. Qian B, Xing M, Cui L, et al. (2011) Antioxidant, antihypertensive, and immunomodulatory activities of peptide fractions from fermented skim milk with Lactobacillus delbrueckii ssp. bulgaricus LB340. J Dairy Res 78, 72-79.

69. Cao WH \& Zhang $\mathrm{CH}$ (2006) Absorption mechanism of peptides in the gastrointestinal tract. Pharm Biotechnol 13, 384-388.

70. Peng XY, Xiong YLL \& Kong BH (2009) Antioxidant activity of peptide fractions from whey protein hydrolysates as measured by electron spin resonance. Food Chem 113, 196-201.

71. Hernández-Ledesma B, Miralles B, Amigo L, et al. (2005) Identification of antioxidant and ACE-inhibitory peptides in fermented milk. J Sci Food Agric 85, 1041-1048.

72. Aloğlu HS \& Oner Z (2011) Determination of antioxidant activity of bioactive peptide fractions obtained from yoghurt. J Dairy Sci 94, 5305-5314.

73. Solieri L, Rutella GS \& Tagliazucchi D (2015) Impact of nonstarter lactobacilli on release of peptides with angiotensinconverting enzyme inhibitory and antioxidant activities during cow milk fermentation. Food Microbiol 51, 108-116.

74. Ramesh V, Kumar R, Singh RRB, et al. (2012) Comparative evaluation of selected strains of lactobacilli for the development of antioxidant activity in milk. Dairy Sci Technol 92, 179-188.

75. Virtanen T, Pihlanto A, Akkanen S, et al. (2007) Development of antioxidant activity in milk whey during fermentation with lactic acid bacteria. J Appl Microbiol 102, 106-115.

76. Sah BNP, Vasijevic T, McKechnie S, et al. (2014) Effect of probiotics on antioxidant and antimutagenic activities of crude peptide extract from yoghurt. Food Chem 156, 264-270.
77. Gjorgievski N, Tomovska J, Dimitrovska G, et al. (2014) Determination of the antioxidant activity in yoghurt. $J$ Hyg Engineer Design 8, 88-92.

78. Lim S-M (2013) Microbiological, physicochemical, and antioxidant properties of plain yoghurt and soy yoghurt. Korean J Microbiol 49, 403-414.

79. Aleksandrova V, Chikov G, Velikova G, et al. (2013) In vivo antioxidant activity evaluation of peptides produced during the fermentation of yoghourt-like dairy products. Bulg $J$ Agric Sci 19, 97-100.

80. Osuntoki A \& Korie I (2010) Antioxidant activity of whey from milk fermented with Lactobacillus species isolated from Nigerian fermented foods. Food Technol Biotechnol 48, 505-511.

81. Parrella A, Caterino E, Cangiano M, et al. (2012) Antioxidant properties of different milk fermented with lactic acid bacteria and yeast. Int J Food Sci Technol 47, 2493-2502.

82. Liu JR, Chen MJ \& Lin CW (2005) Antimutagenic and antioxidant properties of milk-kefir and soymilk-kefir. J Agric Food Chem 53, 2467-2474.

83. Kesenkaş H, Dinkçi N, Seçkin K, et al. (2011) Antioxidant properties of kefir produced from different cow and soya milk mixtures. Tar Bil Der 17, 253-259.

84. Gagnon M, Savard P, Rivière A, et al. (2015) Bioaccessible antioxidants in milk fermented by Bifidobacterium longum subsp. longum strains. Biomed Res Int 2015, 169381.

85. Azcarate-Peril MA, Sikes M \& Bruno-Barcena JM (2011) The intestinal microbiota, gastrointestinal environment and colorectal cancer: a putative role for probiotics in prevention of colorectal cancer? Am J Physiol Gastrointest Liver Physiol 301, G401-G424.

86. Revilla I, Gonzalez-Martin MI, Vivar-Quintana AM, et al. (2016) Antioxidant capacity of different cheeses: affecting factors and prediction by near infrared spectroscopy. J Dairy Sci 99, 5074-5082.

87. Lucas A, Andueza D, Rock E, et al. (2008) Prediction of dry matter, fat, $\mathrm{pH}$, vitamins, minerals, carotenoids, total antioxidant capacity, and color in fresh and freeze-dried cheeses by visible-near-infrared reflectance spectroscopy. J Agric Food Chem 56, 6801-6808.

88. Lucas A, Rock E, Chamba JF, et al. (2006) Respective effects of milk composition and the cheese-making process on cheese compositional variability in components of nutritional interest. Lait 86, 21-41.

89. Pattorn S \& Hongsprabhas P (2013) Effect of coagulants on antioxidant capacity of milk protein curds and their tryptic hydrolysates. J Food Biochem 37, 203-211.

90. Gupta A, Mann B, Kumar R,, et al. (2010) Identification of antioxidant peptides in Cheddar cheese made with adjunct culture Lactobacillus casei ssp. casei 300. Milchwissenschaft 65, 396-399.

91. Barac M, Pesic M, Zilic S, et al. (2016) Protein profiles and total antioxidant capacity of water-soluble and waterinsoluble fractions of white brined goat cheese at different stages of ripening. Int J Food Sci Technol 51, 1140-1149.

92. Parvin S, Rahman MM, Shimazaki K-I, et al. (2010) A comparative study of the changes in different parameters and in the antioxidant activity of Dhaka- and Gouda-type cheeses during ripening. Milchwissenschaft 65, 161-165.

93. Gupta A, Mann B, Kumar R, et al. (2009) Antioxidant activity of Cheddar cheeses at different stages of ripening. Int J Dairy Technol 62, 339-347.

94. Bottesini C, Paolella S, Lambertini F, et al. (2013) Antioxidant capacity of water soluble extracts from Parmigiano-Reggiano cheese. Int $J$ Food Sci Nutr 64, 953-958. 
95. Abadia-Garcia L, Cardador A, del Campo STM, et al. (2013) Influence of probiotic strains added to cottage cheese on generation of potentially antioxidant peptides, anti-listerial activity, and survival of probiotic microorganisms in simulated gastrointestinal conditions. Int Dairy $J \mathbf{3 3}$, 191-197.

96. Díaz-Castro J, Pérez-Sánchez LJ, Ramírez López-Frías M, et al. (2012) Influence of cow or goat milk consumption on antioxidant defence and lipid peroxidation during chronic iron repletion. Br J Nutr 108, 1-8.

97. Zunquin G, Rouleau V, Bouhallab S, et al. (2006) Iron and exercise induced alterations in antioxidant status. Protection by dietary milk proteins. Free Radic Res 40, 535-542.

98. Zemel MB \& Sun XC (2008) Dietary calcium and dairy products modulate oxidative and inflammatory stress in mice and humans. $J$ Nutr 138, 1047-1052.

99. Sun X \& Zemel MB (2008) Calcitriol and calcium regulate cytokine production and adipocyte-macrophage cross-talk. J Nutr Biochem 19, 392-399.

100. Broccali G, Berti M, Pistolesi E, et al. (2005) Hydrolyzed milk-serum peptides reduce body weight and fat content of dietary obese rats ameliorating their antioxidant status and liver functions. Panminerva Med 47, 123-129.

101. Bruckbauer A \& Zemel MB (2009) Dietary calcium and dairy modulation of oxidative stress and mortality in aP2-Agouti and wild-type mice. Nutrients 1, 50-70.

102. Jenkinson SG, Lawrence RA, Burk RF, et al. (1982) Effects of copper deficiency on the activity of the selenoenzyme glutathione-peroxidase and on excretion and tissue retention of ${ }^{75} \mathrm{SeO}_{3}^{2-}$. J Nutr 112, 197-204.

103. Balevska PS, Russanov EM \& Kassabova TA (1981) Studies on lipid peroxidation in rat liver by copper deficiency. Int J Biochem 13, 489-493.

104. Lynch SM \& Strain JJ (1990) Effects of skimmed milk powder, whey or casein on tissue trace element status and antioxidant enzyme activities in rats fed control and copper-deficient diets. Nutr Res 10, 449-460.

105. Rohit S, Rajeev K, Meena K, et al. (2014) Dietary supplementation of milk fermented with probiotic Lactobacillus fermentum enhances systemic immune response and antioxidant capacity in aging mice. Nutr Res 34, 968-981.

106. Bay BH, Lee YK, Tan BKH, et al. (1999) Lipid peroxidative stress and antioxidative enzymes in brains of milksupplemented rats. Neurosci Lett 277, 127-130.

107. Zommara M, Tachibana N, Sakono M, et al. (1996) Whey from cultured skim milk decreases serum cholesterol and increases antioxidant enzymes in liver and red blood cells in rats. Nutr Res 16, 293-302.

108. Cornelli U, Bondiolotti G, Battelli G, et al. (2015) Activity of 30 different cheeses on cholesterol plasma levels and Oxidative Balance Risk Index (OBRI) in a rat model. Int $J$ Food Sci Nutr 66, 383-390.

109. Bo-Young S, Spengler B, Roempp A, et al. (2012) Effects of unripened cheese supplements on lipid and antioxidant status in hypercholesterolemic SD rats. J Korean Soc Food Sci Nutr 41, 65-72.

110. Zemel MB, Sun X, Sobhani T, et al. (2010) Effects of dairy compared with soy on oxidative and inflammatory stress in overweight and obese subjects. Am J Clin Nutr 91, 16-22.

111. Stancliffe RA, Thorpe $T$ \& Zemel MB (2011) Dairy attentuates oxidative and inflammatory stress in metabolic syndrome. Am J Clin Nutr 94, 422-430.

112. Abedini M, Falahi E \& Roosta S (2015) Dairy product consumption and the metabolic syndrome. Diab Metab Syndr 9, 34-37.
113. Babio N, Becerra-Tomás N, Martínez-González MÁ, et al. (2015) Consumption of yoghurt, low-fat milk, and other low-fat dairy products is associated with lower risk of metabolic syndrome incidence in an elderly Mediterranean population. J Nutr 145, 2308-2316.

114. Dugan CE, Barona J \& Fernandez ML (2014) Increased dairy consumption differentially improves metabolic syndrome markers in male and female adults. Metab Syndr Relat Disord 12, 62-69.

115. Michaëlsson K, Wolk A, Melhus H, et al. (2017) Milk, fruit and vegetable, and total antioxidant intakes in relation to mortality rates: cohort studies in women and men. Am J Epidemiol 185, 345-361.

116. Cui X, Zuo PP, Zhang Q, et al. (2006) Chronic systemic d-galactose exposure induces memory loss, neurodegeneration, and oxidative damage in mice: protective effects of $R$ - $\alpha$-lipoic acid. J Neurosci Res $\mathbf{8 4}, 647-654$.

117. Song X, Bao MM, Li DD, et al. (1999) Advanced glycation in d-galactose induced mouse aging model. Mech Ageing Dev 108, 239-251.

118. Hao L, Huang H, Gao JY, et al. (2014) The influence of gender, age and treatment time on brain oxidative stress and memory impairment induced by d-galactose in mice. Neurosci Lett 571, 45-49.

119. Cui X, Wang LN, Zuo PP, et al. (2004) d-Galactose-caused life shortening in Drosophila melanogaster and Musca domestica is associated with oxidative stress. Biogeronto$\log y \mathbf{5}, 317-325$.

120. Utkualp N \& Ozdemir A (2015) Oxidative stress and chronic diseases. Oxid Commun 38, 1690-1696.

121. Moylan JS \& Reid MB (2007) Oxidative stress, chronic disease, and muscle wasting. Muscle Nerve 35, 411-429.

122. Michaelsson K, Wolk A, Langenskiold S, et al. (2014) Milk intake and risk of mortality and fractures in women and men: cohort studies. BMJ 349, g6015.

123. Prasad K \& Dhar I (2014) Oxidative stress as a mechanism of added sugar-induced cardiovascular disease. Int J Angiol 23, 217-226.

124. Power-Grant O, McCormack WG, De Cap MR, et al. (2016) Evaluation of the antioxidant capacity of a milk protein matrix in vitro and in vivo in women aged $50-70$ years. Int J Food Sci Nutr 67, 325-334.

125. Hunter DC, Brown R, Green T, et al. (2012) Changes in markers of inflammation, antioxidant capacity and oxidative stress in smokers following consumption of milk, and milk supplemented with fruit and vegetable extracts and vitamin C. Int J Food Sci Nutr 63, 90-102.

126. Zavorsky GS, Kubow S, Grey V, et al. (2007) An open-label dose-response study of lymphocyte glutathione levels in healthy men and women receiving pressurized whey protein isolate supplements. Int J Food Sci Nutr 58, 429-436.

127. Campbell CG, Brown BD, Dufner D, et al. (2006) Effects of soy or milk protein during a high-fat feeding challenge on oxidative stress, inflammation, and lipids in healthy men. Lipids 41, 257-265.

128. Önning G, Akesson B, Oste R, et al. (1998) Effects of consumption of oat milk, soya milk, or cow's milk on plasma lipids and antioxidative capacity in healthy subjects. Ann Nutr Metabol 42, 211-220.

129. Ravn-Haren G, Bugel S, Krath BN, et al. (2008) A short-term intervention trial with selenate, selenium-enriched yeast and selenium-enriched milk: effects on oxidative defence regulation. BrJ Nutr 99, 883-892. 
130. Hoac T, Stagsted J, Lundh T, et al. (2008) Short-term effects of selenium supplementation of cows' feed on the content and distribution of selenium, copper and zinc in cow milk, whey and blood plasma. J Dairy Res 75, 326-334.

131. Ejtahed HS, Mohtadi-Nia J, Homayouni-Rad A, et al. (2012) Probiotic yoghurt improves antioxidant status in type 2 diabetic patients. Nutrition 28, 539-543.

132. Asemi Z, Jazayeri S, Najafi M, et al. (2012) Effect of daily consumption of probiotic yoghurt on oxidative stress in pregnant women: a randomized controlled clinical trial. Ann Nutr Metabol 60, 62-68.
133. Fabian E \& Elmadfa I (2007) The effect of daily consumption of probiotic and conventional yoghurt on oxidant and antioxidant parameters in plasma of young healthy women. Int J Vitam Nutr Res 77, 79-88.

134. Nam HS, Lee KA, Lee YJ, et al. (2006) Effects of the fermented milk intake on human antioxidant activity and blood alcohol concentration. Food Sci Biotechnol 15, 82-85.

135. Kullisaar T, Songisepp E, Mikelsaar M, et al. (2003) Antioxidative probiotic fermented goats' milk decreases oxidative stress-mediated atherogenicity in human subjects. Br J Nutr 90, 449-456. 